\title{
CITATION:
}

Ciccolini, G. \& Stylianides, G. J. (in press). Teaching to listen, question, and ponder: An investigation into promoting an enquiring atmosphere in a mathematics classroom. Journal of Educational Research in Mathematics.

\section{Teaching to listen, question, and ponder: An investigation into promoting an enquiring atmosphere in a mathematics classroom}

\author{
Gessica Ciccolini \\ IIS Montale-Nuovo IPC, Genova, Italy \\ Gabriel J. Stylianides \\ University of Oxford, UK
}

Author Note: This paper is based on the masters dissertation of the first author, conducted under the supervision of the second author at the University of Oxford, UK. 


\begin{abstract}
$\underline{\text { Abstract }}$
This study reports on a classroom-based intervention that lasted eight lessons with the particular focus of exploring whether and how specific activities, strategies, and questions may promote an enquiring atmosphere in a mathematics classroom, i.e., a classroom environment in which students feel safe to investigate new mathematical ideas in order to produce, share, and test their conjectures in search for a proof. Although many researchers agree on the central role that conjectures and proofs should play in all students' mathematical experiences, many students find it difficult to engage with conjecturing and proving. In this paper we argue that the classroom atmosphere has a crucial influence in helping students to overcome these difficulties and we focus our investigation on an English secondary mathematics classroom taught by the first author. Students' responses to questionnaires, prompts, tasks, and interview questions were analysed in order to evaluate the impact of the intervention. The analysis suggests that specific activities, strategies, and questions can be used by teachers to facilitate an enquiring classroom atmosphere. However, for these to be effective, the teacher needs to explicitly teach students how to listen, question, and ponder in order to give students the tools to formulate conjectures and proofs.
\end{abstract}




\section{Introduction}

Johnston-Wilder and Mason (2005) state that mathematical thinking only arises when conjectures or assertions to be justified are formulated. In other words, learners should be encouraged to investigate problems, state their conjectures, and try to prove or refute them. Moreover, Johnston-Wilder and Mason (2005, p. 243) suggest that "one of the most important things that a school can contribute in the way of developing learners' powers is to engender an enquiring atmosphere" where students feel safe to share their mathematical ideas and receive constructive feedback. Therefore, promoting students' engagement in conjecturing and proving activity, on the one hand, and developing an enquiring atmosphere, on the other hand, are two sides of the same coin.

Although doing and learning mathematics within the discipline usually involves creating and proving conjectures, it is not common to see the same practice in school mathematics classrooms; the classroom practices of teacher-researchers such as Deborah Ball (Ball \& Bass, 2000, 2003; Stylianides, 2007, 2016), Magdalene Lampert (Lampert, 1990, 1992, 2001), and Vicky Zack (Reid, 2002; Zack, 1997) constitute notable exceptions. However, as pointed out by Stylianides, Stylianides, and Weber (2017), in recent years there has been a growing interest in introducing the activity of proving in primary and secondary schools.

Curriculum frameworks in different countries are now calling for an important role for conjecturing and proving in the mathematical experiences of all students and as early as the elementary school. Examples can be found in the United States, in the Common Core State Standards (National Governors Association Center for Best Practices \& Council of Chief State School Officers [NGA \& CCSSO], 2010) and the influential document of the Principles and Standards for School Mathematics published in 2000 by the National Council of Teacher of Mathematics (NCTM, 2000) and, in England, in the latest National Mathematics Curriculum (Department for Education, 2013). For example, one of the three core aims that the National Mathematics Curriculum in England sets for students of all ages relates to proof: "[Students should] reason mathematically by following a line of enquiry, conjecturing relationships and generalisations, and developing an argument, justification or proof using mathematical language" (Department for Education, 2013, p. 3). A similar statement was also included in the Principles and Standards (NCTM, 2000) powerfully stating that, if learners should learn to conjecture, formulate mathematical arguments and respond to others' comments, then it is crucial to create an environment that encourages these activities. In such a learning environment, students should feel safe to share their ideas and believe that their thinking is listened to and valued. Differences should be appreciated and learners should respect others' thoughts and be able to critically analyse them (Ball \& Bass, 2003).

Being aware of the central role that teachers play in creating quality classroom environment (Yackel \& Cobb, 1996; Stylianides, 2016), we designed an intervention that was implemented by the first author in a Year 9 classroom (13-14 year-olds) in a secondary comprehensive school in England. The particular focus of the intervention was to explore whether and how specific activities, strategies, and questions may promote an enquiring atmosphere in a mathematics classroom, whereby with enquiring atmosphere we refer to a classroom 
environment in which students feel safe to investigate new mathematical ideas in order to produce, share, and test their conjectures in search for a proof.

In brief, the intervention, which lasted over eight lessons, focused on teaching learners to listen, question, and ponder. The activities included the 'three before me' (3B4ME) strategy to encourage independence, and think-pair-share activities valuing the state of being stuck in the problem solving process. In relation to strategies, pupils were encouraged to write some examples to conjecture, to explicitly state their conjectures, and to use different representations (algebraic, verbal, pictorial) to write proofs. Eight types of oral questions were gradually introduced in the lessons as well as two types of written questions (general statements and collections of examples).

\section{Literature review}

In the first part of this section we will clarify the meaning we will attribute to 'conjecture' and 'proof' and we will focus on the processes involved in the proving activity. In the second part we will focus on the classroom atmosphere that can support this activity and we will reflect on the role of the teacher in promoting an enquiring atmosphere. Finally, we will concentrate on the role that specific questioning can play in supporting learners in conjecturing and producing proofs.

\subsection{The proving activity}

\subsubsection{Conjectures}

A conjecture is a mathematical statement whose truth seems plausible but is still uncertain. In other words, it is a "reasoned hypothesis about a general mathematical relation based on incomplete evidence" (Stylianides, 2008, p. 11). This definition highlights two important aspects of a conjecture.

First, a conjecture needs to be reasoned and plausible, and arbitrary guesses cannot be considered as conjectures. Indeed, a conjecture should be sustained by preliminary work, which can derive from different ways of reasoning (e.g. pattern observing, deducing by analogy) and should suggest the possible truth of the statement (Fischbein, 1987).

Second, the notion of 'hypothesis' highlights the uncertainty of the conjecture because its truth or falsity still has to be showed. However, as Reid (2002) points out, different people may judge the correctness of a statement in different ways. In other words, someone can still have doubts on the truth of a statement while others could have already accepted it as true. This tension can be useful in a classroom in order to emphasise the importance of producing a proof or a counter-example to confirm or reject a conjecture. As Mason, Burton, and Stacey (1982) suggest, learners should be encouraged not to believe their conjectures but to be ready to test them and, if necessary, modify them. 


\subsubsection{Proofs}

In the mathematics education research literature different meanings are attributed to the notion of proof (Reid, 2005). Therefore, it is important for us to clarify the meaning that we will attribute to proof in this study.

While Rav (1999, p. 13) defines proof as the way that mathematicians use to "verify that a proposed solution to a problem is indeed a solution", Harel and Sowder (1998) highlight the subjectivity that a proof holds by stating that a proof is what shows truth to a person or a community. In addition to showing the validity of a mathematical argument, according to Hersh (1993) a proof should convince and explain. A proof should explain why a mathematical statement is always true using facts and reasonings understandable to the readers. Moreover, a proof should convince yourself, a friend, and a sceptic (Mason et al., 1982). If convincing yourself is often an easy task, convincing a friend should imply to justify every step of the argument. However, the last phase involves convincing a person who would doubt every assumption forcing who produced the proof to use an appropriate mathematical language and correct mathematical statements. In other words, a proof should avoid "requir[ing] the reader to make a leap of faith" (Stylianides \& Stylianides, 2009a, p. 243).

The previous ideas are considered in Stylianides' (2007) definition of proof, which is the one we will use in this work. We also note that, following Stylianides (2007), we will use the term proving to refer to the activity in search for a proof. Below we report Stylianides' definition of proof in its entirety for clarity and completeness.

Proof is a mathematical argument, a connected sequence of assertions for or against a mathematical claim, with the following characteristics:

1. It uses statements accepted by the classroom community (set of accepted statements) that are true and available without further justification;

2. It employs forms of reasoning (modes of argumentation) that are valid and known to, or within the conceptual reach of, the classroom community; and

3. It is communicated with forms of expression (modes of argument representation) that are appropriate and known to, or within the conceptual reach of, the classroom community.

(Stylianides, 2007, p. 291, italics in original)

As Stylianides (2007) explains, the definition aims to achieve a defensible balance between disciplinary norms and practices, on the one hand, and accessibility of the mathematical ideas by the members of a classroom community, on the other hand. Regarding the latter, a proof should involve definitions and notions known by the classroom community, it should use modes of argumentation that are understandable by learners, and it can utilise a variety of representations (such as verbal, pictorial, algebraic) that are accessible to the students in a classroom.

Regarding the third point, during some lessons on proofs with prospective teachers, Perks and Prestage (1995) found that general arguments using words or diagrams were not accepted as proofs. On the other hand, in a study on algebraic proofs with 14- and 15-year old students, 
learners preferred proofs using everyday language and pictures rather than algebra (Healy \& Hoyles, 2000). A reason behind this preference was that the first proofs were clearer in explaining the truth of a statement, but students were reluctant to use them because they perceived algebra to be the preferred mode of representation by their teacher. Therefore, it seems important to give pupils the opportunity to access and use different representations without believing that "mathematical truth is determined [only] when the answer is ratified by the teacher" (Lampert, 1990, p. 32, emphasis in original).

\subsubsection{The proving activity}

In school mathematics proofs are often presented as formal processes not connected with other mathematical activities and the activity of searching for a proof mainly focuses on the end product, which is the proof itself (Stylianides, 2008). However, this presentation obscures the investigative and empirical aspects that are usually employed by mathematicians when they investigate a mathematical phenomenon. Therefore, following Stylianides (2008) and Stylianides and Ball (2008), we will consider the proving activity in a broader way.

In addition to the formulation of proof or non-proof arguments, our consideration will include other processes that precede them and also play an important role in promoting an enquiring atmosphere (Mason et al., 1982; Reid \& Knipping, 2010). The processes (also referred to as 'phases') we will consider are the following:

- Specialising and specialising back

- Generalising

○ Pattern observing

- Conjecturing

- Providing support to mathematical claims

○ Providing proofs

○ Providing non-proof arguments

- Evaluating

During the proving activity these processes may occur in different orders, different repetitions, or may not necessarily occur at all (Cañadas \& Castro, 2005). We discuss each of these processes in the following paragraphs.

During the initial attempts to investigate a question (e.g. What do you notice when you add two odd numbers? Can you explain why it works?), a good practice could be to try some examples in order to get a better understanding of the statement. Mason (1999) refers to this process as specialising, which is "looking at particular cases of a general statement" (p. $\mathrm{x}$ ). In the previous example, it would be trying some sums of odd numbers. Another instance of specialising can occur when some cases are tested after making a conjecture. This process can be called specialising back, which corresponds to the testing process explained by Reid (2002, p. 14) as "a specialisation and a comparison" to confirm or refute the conjecture. Although the specialising activity can be helpful to gather some data on the problem, Mason and Pimm (1984) state that this is not the main purpose of the activity when a proof is searched. Another aim of producing a collection of examples should be to try to see the general through the particular, trying to determine the general features that the different examples have in common. 
Once some common features are observed and abstracted from particular examples, the generalising process begins (Mason, 1999). In this phase it is possible to distinguish between at least two different processes. First, after presenting several examples it can happen that a pattern is observed or there could be just a sense of it. This is when the generalising process starts and it can be described as pattern observing (or 'identifying a pattern' in Stylianides' [2008] framework), although in the literature there is not a standard term to describe this stage (Reid \& Knipping, 2010). However, as Bills and Rowland (1999) point out, a challenge in generalising from patterns is to encourage learners to make structural generalisations rather than empirical generalisations. In other words, it is fundamental that the generalisation arises from an understanding of the structure that underpins the examples rather than from an empirical regularity observed in the examples. Moreover, in their study with a group of preservice elementary teachers, Zazkis and Liljedahl (2002) notice that although most of the teachers were able to identify a pattern not all of them were able to generalise it.

The second process under 'generalising' is conjecturing, which can be described as the phase of "sensing or guessing that something might be true and investigating its truth" (Mason et al., 1982 , p. 64). Although this process is related to the pattern observing one, the two processes present some differences. As Stylianides (2008) points out, a conjecture is stated with doubts about its truth while stating a pattern does not necessarily imply doubts about it. Moreover, conjecturing has a broader domain than pattern observing: while the latter refers to the specific observed cases, the former refers to general cases (Reid, 2002).

The relevance of the conjecturing activity is highlighted by Mason's $(1999$, p. 8$)$ assertion that "mathematical thinking is best supported by adopting a conjecturing attitude". However, as Polya (1965) suggested, it is fundamental to remind learners to conjecture, but not to believe their conjectures. While the exploration involved in the activities before and during conjecturing often leads to discoveries, only a proof can confirm the result. Nevertheless, the literature suggests that many students believe that a collection of examples is sufficient to show the truth of an argument (for a review, see Harel \& Sowder, 2007) and therefore it becomes worthwhile to deepen the knowledge of the activities that can be involved after conjecturing.

The aim of the process that can follow the conjecturing activity is to show the truth of the conjecture and can involve the formulation of proofs or non-proof arguments. Stylianides (2008) captures proofs and non-proof arguments under the broader process of providing support to mathematical claims. A mathematical argument can be considered a proof if it satisfies the conditions analysed in the previous section, while it will be a non-proof argument if it falls short in meeting some of the criteria for proof. For example, generalisations founded on checking some possible cases or on the use of other mathematical facts that are not yet considered true by the classroom community have to be considered non-proof arguments. In order to help students to realise the limitations of empirical arguments, it can be helpful to introduce tasks that present a plausible pattern for the first cases which finally fails (Stylianides $\&$ Stylianides, 2009b). Moreover, as we will discuss in Section 4.2.2.3 we found useful in this intervention to discuss the task 'odd + odd $=$ even' with students in order to emphasise the 
necessity of only using statements already accepted as true by the classroom community (in this example, 'even + even $=$ even').

Finally, the last process we will discuss is one that has been considered by Stylianides and Stylianides (2009a). It consists of asking learners to evaluate their produced mathematical argument, stating whether they consider it to be a proof or not. At the end of their study with 39 prospective teachers, the authors found that the percentages of teachers who produced an empirical argument and claimed it constituted a proof dropped from $10 \%$ to $3 \%$. Thus, it can be useful for a teacher to ask students to evaluate their own arguments in order to be able to distinguish between learners who have an empirical conception of proofs and those who are aware of the limitations of empirical arguments but, for different reasons, may not be able to produce proofs (for further discussion of this issue, see Stylianides \& Stylianides, in press).

To sum up, several processes may be involved while conjecturing and proving: writing some examples or specific examples (specialising or specialising back), looking for a pattern (pattern observing), formulating a conjecture (conjecturing), showing the validity of the conjecture (providing support to mathematical claims), and assessing the produced mathematical argument (evaluating). Being aware of these processes can be helpful for teachers that would like to engage learners in the proving activity and promote an enquiring atmosphere in their classrooms.

\subsection{Enquiring atmosphere}

In this section we will describe what classroom atmosphere may support the proving activity, discussing how an enquiring atmosphere might look like and what factors may contribute to its development. An enquiring atmosphere is one in which learners produce, share, and test their conjectures looking for a proof. In such an atmosphere it is worthwhile to receive suggestions in order to modify or support each other's conjectures (Love \& Mason, 1992). In other words, constructive feedback can help learners to ponder on their conjecture and consequently reformulate or try to prove it. The importance of promoting such an atmosphere is related to "the social importance of developing a caring, listening, yet challenging way of interacting" with other people (Johnston-Wilder \& Mason, 2005, p. 243).

Developing an enquiring atmosphere is not easy and some sets of norms can be established in the classroom to facilitate it. Yackel and Cobb (1996) distinguish between social norms and sociomathematical norms. Social norms are norms that can be valid in any classroom, such as expecting students to explain their solutions and reasoning. Sociomathematical norms are norms strictly related to mathematics classrooms, such as deciding what explanations can be considered mathematically acceptable. In any case, classroom environments are often very different and can be influenced by factors that cannot be generalised, such as the relationship between the teacher and learners or the relationship between peers (Mason \& Johnston-Wilder, 2006). However, some common features that may facilitate an enquiring atmosphere can be identified as we discuss below.

In an enquiring atmosphere "pupils are encouraged not to take assertions as facts, but to investigate matters for themselves" (Love \& Mason, 1992, p. 39). This is a crucial point but also, according to our experience, one of the most difficult ones to achieve. Indeed, students 
frequently depend on the teacher's hints in order to solve a task or to check a solution. In Lampert's words (1990, p. 32) "in school the truth is given in the teacher's explanations and the answer book". However, the first author has always been interested in offering her students the opportunity of doing mathematics rather than applying mathematics, which is part of what motivated the investigation reported in this paper. An investigative approach is usually fundamental in doing mathematics, involving conscious guesses followed by zig-zag reasonings that can eventually lead to a proof or refutation going through examples and counter-examples (Lakatos, 1976). Therefore, an essential feature of an enquiring atmosphere seems to be increasing students' autonomy in solving and checking a mathematical problem, emphasising in students the belief that, "in mathematics the authority lies within mathematics, not with individual people" (Johnston-Wilder \& Mason, 2005, p. 238) and, in particular, not with the teacher.

A strategy that can be useful in order to encourage students not to think of the teacher as the first source of authority is the 3B4ME (three before me) strategy (Smith, 2010). The ' $3 \mathrm{~B}$ ' stands for brain, book, and buddy. These are the three steps that students should go through before asking the teacher for help. First, they should use their brain, which means thinking of what they know in order to attempt to solve the problem. Second, they should use their notebook in order to look for concepts, examples, or strategies already studied. Third, students should discuss their ideas and doubts with a friend (the buddy) in order to work on the task together. The third stage emphasises the richness of working in a classroom community, valuing each other's opinions and ideas.

Another important feature of an enquiring atmosphere is to encourage pupils to share their conjectures even if they are half-formed ideas (Gilderdale, 2007). Indeed, sharing conjectures is valuable at least for two reasons. First, saying the conjecture aloud or trying to write it on a piece of paper encourages the student to look at the conjecture from a distance helping to clear the mind, to clarify one's thoughts, and to start evaluating it (Mason, 1999). This practice allows learners to personally reflect on their mathematical conjectures and methods. Second, sharing a conjecture with peers, either in pairs or in whole class discussions, allows learners to receive feedback from each other on their ideas (Lampert, 1990), granting the students some ownership of their learning. The first author has found the latter practice invaluable for several reasons. First, it encourages learners to value others' mathematical ideas reinforcing a respectful classroom culture. Second, it makes students use an appropriate language to make their conjectures understandable to others. Third, it stimulates learners both to reflect on others' conjectures and on the feedback on their own conjectures. In both cases learners are required to ponder and question others' mathematical comments. According to Lampert (2001, p. 66), "by reflecting on whether their own assertions and those of their classmates were reasonable" learners have the opportunity to turn "over ideas and procedures in their minds" along with practising mathematical concepts and rules with a highest chance of remembering them.

However, it has to be noted that formulating and offering conjectures implies taking a risk (Mason \& Johnston-Wilder, 2004). This risk involves being open to considering possible adjustments and revisions, being willing to admit that a conclusion is wrong and to change it, and being ready to question one's own mathematical ideas in order to convince others of their 
validity. According to Polya (1954, pp. 7-8), these are three 'moral qualities' required to do mathematics and part of the "inductive attitude [which] aims at adapting our beliefs to our experience as efficiently as possible". Therefore, in an enquiring atmosphere any sensible conjecture should be praised, regardless of its correctness, in order to stress the value of taking the risk of sharing a mathematical idea and getting feedback on it (Mason, 2002b). As suggested by Lampert (1990), conjectures can then be collected on the whiteboard together with the names of the students who offered them and the class can be invited to test them and comment on them. In this way, the responsibility of verifying the correctness of the conjecture is again given to the learners and does not feed the belief that the teacher is "the [only] source of right answers" (Ollerton \& Watson, 2001, p. 90).

Related to encouraging learners to share conjectures and to value risk-taking, another ingredient that can contribute to developing an enquiring atmosphere is praising students for changing their mind (Mason, 2002b). Indeed, pupils may need to modify or change their previous conjectures after listening to others' suggestions or ideas. As Johnston-Wider and Mason (2005, p. 243) argued, "if modifying conjectures is valued and praised, then mathematical thinking is much more likely to flourish". However, Fischbein (1987) points out that, although pupils may be rationally aware that their original conjecture was wrong, they are often reluctant to replace it with a more acceptable one because initial intuitions are usually strong. Therefore, it may be useful to explicitly tell pupils that they might find it difficult and annoying to change a wrong conjecture but that it is how responsible mathematicians work and how learning is more likely to take place (Yackel \& Hanna, 2003).

In the process of establishing a safe environment for learners to review their mathematical statements and to comment on one another's statements, the zig-zag path between attempts to prove conjectures and subsequent refinements or refutations should be valued (Zack, 1997) as well as the status of being 'stuck' (Mason et al., 1982). The first author has often heard students saying: 'Miss, I am stuck. What should I do now?', expressing a sense of frustration and powerlessness. However, learners should be made aware that being stuck "is an honourable and positive state, from which much can be learned" (Mason et al., 1982, p. 49). Therefore, establishing a classroom awareness of the possibility not to know how to solve a problem and the opportunity to try to cope with these moments without giving up or necessarily depending on the teacher's help appears to be another feature of an enquiring atmosphere. In an enquiring atmosphere struggling with a problem should be valued and praised, and pupils should be fostered to express their doubts out loud encouraging them to help each other (Mason, 2002b). In this way, "learning becomes more efficient as well as more satisfying" (Mason, 2002b, p. 257). Nevertheless, although it is critical to recognise being stuck as a possible state while solving mathematical problems, it is also important for learners to develop strategies to get unstuck. According to Mason (1999), the best strategy to get unstuck is to specialise, by writing some examples in order to have a better sense of what the problem states. Another useful strategy is to explicitly write what is known and what is asked in order to start to get a sense of possible relationships between the question and its solution. Finally, pupils should be encouraged to clearly state when they get unstuck in order to emphasise the sense of pleasure of the AHA! moments (Mason et al., 1982) and to be able to possibly re-use the strategies that helped them to get unstuck in other tasks. 
According to Mason (2002b), another essential feature that may contribute to developing an enquiring atmosphere is to adopt a conjecturing stance by the teachers themselves, trying to investigate problems and considering what students propose as a conjecture. Adopting a conjecturing stance requires that teachers produce conjectures on a mathematical task and subsequent refutations or proofs (Bieda, 2010). In other words, it requires that teachers actually do mathematics themselves and reflect on the pleasure of discovering new mathematical results but also the difficulty of coping with moments of struggle. This attitude may help teachers "to recognise how essential confidence is and to create a supportive environment" (Mason et al., 1982, p. 152) where students can feel safe to express their mathematical ideas. In addition to this, Stein et al. (2008) suggest not only to solve a mathematical task but to anticipate likely student solutions to it. In their words, "teachers need to devise and work through as many different solution strategies as they can" (Stein et al., 2008, p. 323). In this way, teachers will be better prepared to respond to students' solutions. However, it has to be considered that this teacher activity would be time consuming for teachers and can also have some negative aspects. Although on the one hand a detailed plan can support teachers in adapting their lessons to learners' needs more easily, on the other hand Love and Mason (1992) point out that a too detailed planning can be counter-productive. Indeed, students' freedom in investigating a task and in producing conjectures may be influenced by the teacher's prior investigations that are in the teacher's mind.

In the interest of supporting a learning environment where learners can formulate conjectures and proofs, teachers' knowledge of proof is important for promoting the proving activity effectively (Bieda, 2010). In a study with secondary mathematics teachers, Knuth (2002a) found that, although teachers recognised various roles of proof in mathematics, they did not consider proof as a tool to promote mathematical understanding. Therefore, many of the teachers believed that proofs were not suitable for secondary students. However, Schoenfeld (1994, p. 76) states that proofs cannot be separated from mathematics because they are "an essential component of doing, communicating, and recording mathematics". In order to emphasise the role of proofs in learning mathematics, it is essential that teachers are aware of the difference between proofs and empirical arguments (Stylianides \& Stylianides, 2009b; Stylianides et al., 2017). In their study with 101 American elementary school teachers, Martin and Harel (1989) found out that $68 \%$ of them believed that an empirical justification qualified as a proof. On the other hand, most of the secondary teachers involved in Knuth's (2002b) study did not accept empirical arguments as proofs for themselves, but they accepted them as proofs from their students. However, as Harel and Sowder (2007) warn, a dangerous consequence of this practice is that students may be led to believe that a collection of examples constitutes a proof.

Consequently, teachers' understanding of proof is essential in order to create a classroom atmosphere where, on the one hand, examples are valued to get a sense of a mathematical problem and formulate conjectures but, on the other hand, proofs are required in order to prove the truth of the statement. In Schoenfeld's words (1994, p. 76):

If students grew up in a mathematical culture where discourse, thinking things through, and convincing were important parts of the engagement with mathematics, then proofs would be seen as a natural part of their mathematics. 
To sum up, several factors may contribute to promoting an enquiring atmosphere in a mathematics classroom as summarised in Table 1. Learners should be encouraged not to depend on the teacher, but to investigate mathematical ideas by themselves and share ideas with their classmates. Their engagement in conjecturing should be praised, even if the conjectures are incomplete or incorrect, and the status of being stuck should be valued as a possible stage to learn. Teachers could facilitate such an environment by also adopting a conjecturing stance themselves, having a solid knowledge of what a proof is and anticipating possible strategies and solutions that their students may use. However, as Mason (2014) points out, these ideas are not universal, because the relationship between teachers and students influence much of what happens in a classroom.

\begin{tabular}{|l|}
\hline Increase students' autonomy - 'three before me' (3B4ME) \\
\hline Encourage students to share conjectures even if not complete \\
\hline Encourage students to give feedback on others' conjectures \\
\hline Value risk-taking in sharing conjectures \\
\hline Value reformulating conjectures \\
\hline Value the status of being stuck \\
\hline Teachers themselves adopt a conjecturing stance \\
\hline Anticipate possible student strategies \\
\hline
\end{tabular}

Table 1. Factors that may promote an enquiring atmosphere

\subsection{Questioning}

In this section, we will discuss some aspects of questioning that can contribute to developing an enquiring atmosphere and may support pupils' conjecturing and proving activity. In the implementation of our study, we were particularly interested in encouraging learners to pose questions to themselves while doing mathematics as well as to pose questions to others while offering conjectures. The importance of questioning in an enquiring atmosphere has been emphasised by Mason et al. (1982) who considered it a fundamental component that can create such an atmosphere. Next, we will consider three aspects of questioning that can support a conjecturing attitude in learners.

Firstly, as discussed in the previous section, a key feature of an enquiring atmosphere is giving the initiative and responsibility of solving a task to students while decreasing their dependency on the teacher. This aspect highlights the importance of questioning learners and encouraging them to query their assumptions rather than giving them answers (Boekaerts, 1997). However, as Lampert (1990) points out, teachers often respond to students' doubts by telling them what they have to do and therefore students may develop the "view of mathematics as a bag of tricks that have to be discovered or revealed" (Mason et al. 1982, p. 115). On the contrary, Mason et al. (1982) suggest posing questions with the aim of supporting learners to focus their attention 
appropriately, prompting them to reason by themselves and developing their mathematical thinking.

Accordingly, the purpose of teachers' questioning becomes crucial in order to support an enquiring atmosphere in the classroom. Teachers should be genuinely interested in what learners are thinking and why they are thinking it (Mason, 2002b). Instead of asking a question to expect a correct answer, which a teacher usually already knows, Watson and Mason (1998) suggest to genuinely enquire into learners' methods and ways of thinking. In order to emphasise the importance of making conjectures, teachers can query students and reason with them rather than focusing on getting quick right answers from students. To facilitate this, students' strategies can be displayed on the board and discussed.

Secondly, another aspect of questioning that can influence an enquiring atmosphere is providing students with thinking time. Questions are most effective when an immediate answer is not required by the teacher but students are encouraged to reflect on it (Ainley, 1987; Mercer \& Dawes, 2008; DfES, 2004; Ingram \& Elliott, 2016). However, in a study with elementary science teachers on wait time, Rowe (1974) found that the average time was 0.9 seconds which prevented most students taking part in the classroom discussion. On the other hand, increasing the wait time highlights once again the emphasis on learners' thinking rather than on the right answer itself. In other words, "the aim is not for discrete right answers to be celebrated, but for a discussion of the ideas to be explored" (Black et al, 2003, p. 39). Therefore, as discussed in the previous section, the state of being stuck should be valued as an opportunity for students to pose questions to themselves and to others as well as to discuss ideas with classmates. Thinking time is also fundamental to encouraging learners to talk to each other and share their doubts (Mason, 2002b).

Thirdly, another aspect of questioning which is related to the development of an enquiring atmosphere is the type of generic questions asked by teachers and students to support a conjecturing stance. In order to encourage learners to reflect on their mathematical reasoning, Schoenfeld (1985) proposes the following three questions:

- What exactly are you doing?

- Why are you doing it?

- How does it help you?

In addition to these questions, Kramarski and Revach (2009) suggest other questions that may be asked to check learners' arguments:

- Is the solution reasonable?

- Can I solve the task differently?

However, if students depend on the teacher's questions in order to investigate a task or get unstuck their dependency on the teacher would be strengthened rather than decreased. Therefore, in an enquiring atmosphere teachers should not be the only questioners and it would be fundamental to work with students on their questioning skills. Students should be able to ask good questions both to themselves and to their peers when they try to convince a friend or a sceptic on the validity of their arguments. As we will explain in detail later, Mason (2002b) 
and Hodgen and Wiliam (2006) formulated a useful list of generic questions that can be used in class in order to "enculturat[e] learners into using specific questions themselves" (Mason, 2002 b, p. 252). In an enquiring atmosphere learners should be encouraged to ask questions at least for the following three reasons: (1) Being able to identify useful questions can help them to formulate conjectures and proofs or to get unstuck; (2) Students who know the answer to a question can be stimulated to question the others and to prompt them rather than giving them the answer; and (3) Learners should feel safe to question and challenge others' conjectures because, in this way, questioning can be used as a vehicle "to elicit student understanding and promote shared learning" (Black et al., 2003, p. 39).

To summarise, in this section we discussed three aspects of questioning that can support a conjecturing attitude in learners. Those aspects are posing questions to students rather than telling them right answers, increasing teachers' wait time, and formulating generic questions on the processes used to solve tasks or to formulate conjectures with the aim to reflect on students' mathematical thinking.

\section{Methodology}

Although the importance of questioning to create an enquiring atmosphere has been emphasised in the literature (Mason et al., 1982), little research has investigated how to promote an enquiring atmosphere in the classroom through the use of oral and written questions. We were also interested in researching what teaching practices may promote such an atmosphere, especially in relation to helping students engage in conjecturing and proving. Specifically, in this paper we aim to address to the following Research Questions (RQs):

- RQ1: What are Year 9 students' beliefs about the atmosphere in their mathematics classroom?

- RQ2: What teaching practices can facilitate an enquiring atmosphere in a mathematics classroom?

- RQ3: What types of oral questions and written questions (general statement or list of examples) may support learners in making conjectures and producing proofs? 


\subsection{Action research method}

The action research method (Elliott, 1978; Stringer, 2008) was adopted in this study. Although there are several definitions for action research (Cohen, Manion, \& Morrison, 2011), a common attribute is the cyclical approach to the study. In particular, the research is constituted by several cycles and each cycle is divided into different phases, which can include the identification of an issue, the plan of the intervention, the implementation of it and the evaluation of the action. The reflection on a cycle will inform the following cycle, creating a "feedback loop in which initial findings generate possibilities for change" (Denscombe, 2010, p. 126) to be implemented later in the research. This school-based research included three cycles as shown in Figure 1.

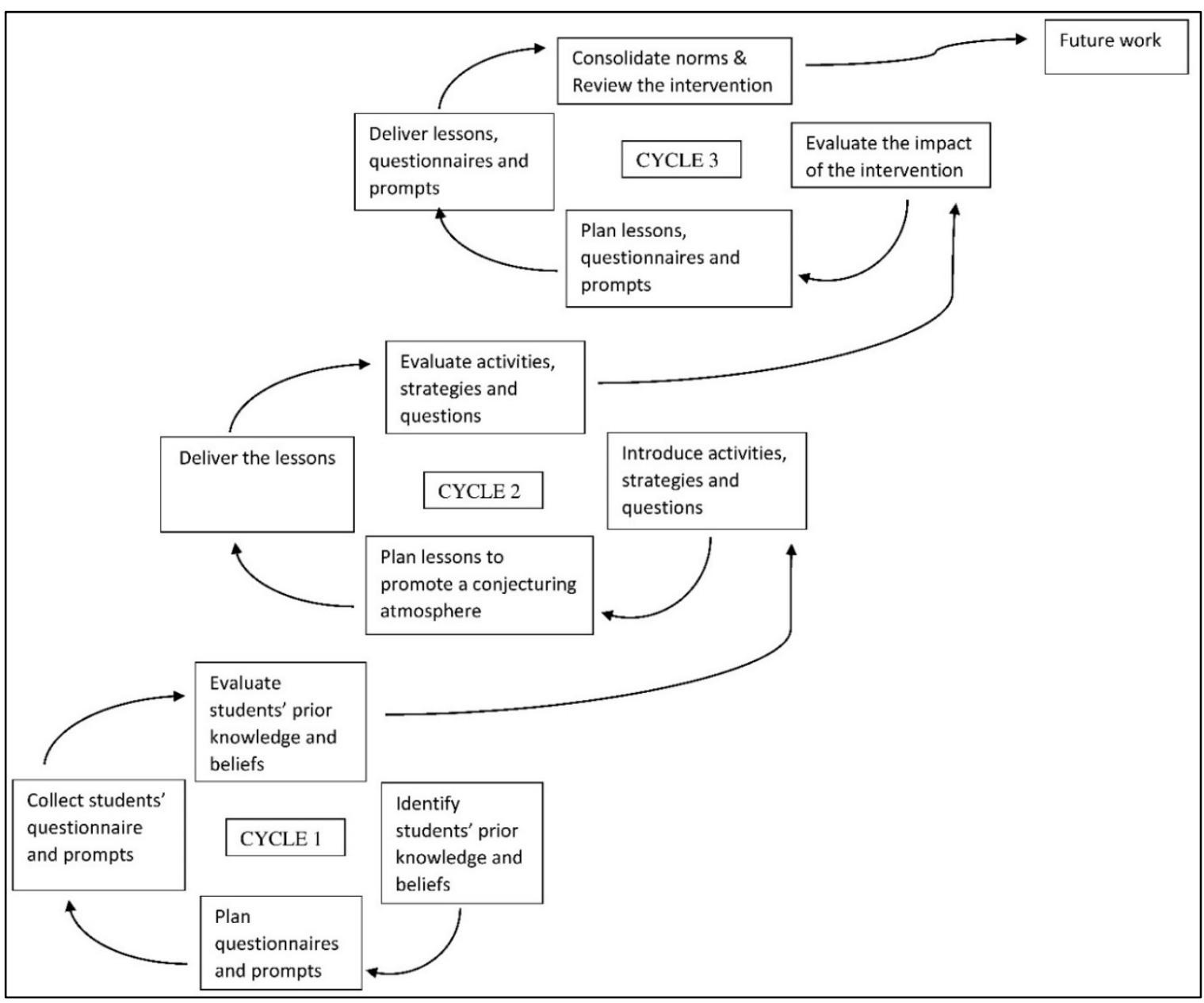

Figure 1. Action research cycles

The results and reflections of each cycle informed the following one. Cycle 1 focused on identifying learners' beliefs about their mathematics classroom atmosphere (addressing RQ1) and their prior knowledge of producing conjectures and proofs (which will not be discussed in this article due to space limitations). Cycle 2 focused on consolidating existing and introducing new practices to support an enquiring atmosphere (addressing RQ2 and RQ3). Cycle 3 focused on conducting and evaluating the intervention (addressing RQ1-RQ3). 


\subsection{Participants and piloting}

The intervention focussed on the first author's Year 9 class (13-14 year-olds) composed by 31 students, 13 girls and 18 boys. Their English National Curriculum attainment levels were in the highest band (between 7c and 8a). The first author collaborated with other teachers in the mathematics department anticipating possible students' answers with them and sharing the results of the intervention. In particular, one teacher taught some lessons planned by the first author to a Year 10 class (14-15 year-olds) with a similar attainment level as the Year 9 class. The lessons and resources were discussed with the collaborating teacher and she taught the lessons before the first author taught the same lessons to the Year 9 class. This organisation was useful and served as a piloting of the lessons/resources to discuss strengths and identify problems prior to implementing them with the research group.

\subsection{Data sources}

In each research cycle we used a variety of research instruments in order to address the three research questions and to provide a means of triangulation. Table 2 displays the desired outcomes for the researchers and for the students following the intervention, the links with the curriculum, and the research questions addressed. The lessons were spread out over five months, from January to May. 


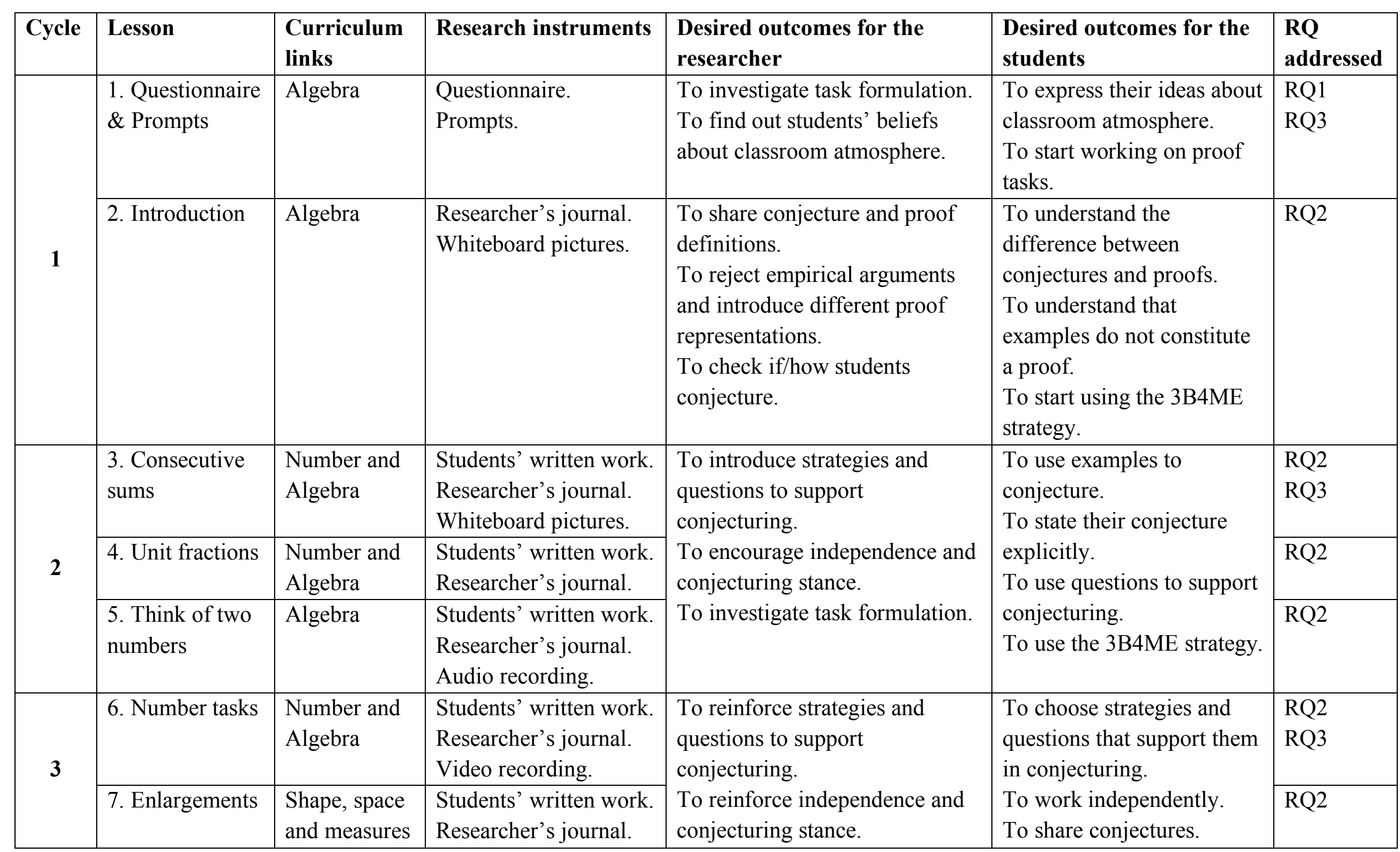




\begin{tabular}{|c|c|c|c|c|c|}
\hline & & Audio recording. & To investigate task formulation. & & \\
\hline $\begin{array}{l}\text { 8. Questionnaire } \\
\text { \& Prompts }\end{array}$ & Algebra & $\begin{array}{l}\text { Questionnaire. } \\
\text { Prompts. } \\
\text { Interviews. }\end{array}$ & $\begin{array}{l}\text { To evaluate students' beliefs } \\
\text { about classroom atmosphere. } \\
\text { To evaluate knowledge on } \\
\text { conjectures and proofs. } \\
\text { To evaluate impact of strategies } \\
\text { and questions. } \\
\text { To investigate task formulation. }\end{array}$ & $\begin{array}{l}\text { To express their ideas about } \\
\text { classroom atmosphere. } \\
\text { To work on proof tasks. } \\
\text { To be aware of strategies } \\
\text { and questions that support } \\
\text { them in conjecturing. }\end{array}$ & $\begin{array}{l}\text { RQ1 } \\
\text { RQ2 } \\
\text { RQ3 }\end{array}$ \\
\hline
\end{tabular}

Table 2. Research cycles, instruments, desired outcomes, and research questions 
In the rest of this section we will describe the rationale and analysis of the research instruments used in the study.

\subsubsection{Questionnaire (see 0)}

The questionnaire was completed at the beginning and at the end of the intervention with only some minor modifications as described below. The questionnaire was designed for three main desired outcomes: finding out pupils' opinions on sharing mathematical ideas and their perceptions of their classroom atmosphere; analysing pupils' knowledge of formulating conjectures and proofs (not discussed in this article); and evaluating whether a general statement or a collection of examples was more helpful to conjecturing and proving. A comparison between the results of the two implementations of the questionnaire contributed to evaluating those outcomes for the Year 9 class.

Question 1 was designed in order to collect information on the first aim. The nine statements to be evaluated were organised around four main themes. First, we were interested in students' opinions on sharing mathematical ideas. In particular, if they found it helpful even if they were wrong, if they felt safe to share them, if they felt that their ideas were valued in class. Indeed, "the children need to know that (...) their contributions are taken into account" (Mathematical Association, 1992, p. 29) in order to feel confident to share their ideas. Second, we were interested in finding out the role of the teacher and of the students considered 'smart' at mathematics. We were aware of the importance "to reduce the dependency on the teacher $(. .$. as judge of correctness and source of ideas" (Love \& Mason, 1992, p. 36) and of the importance of being confident in disagreeing with the students considered 'smart' at mathematics in order for everyone to take part in conjecturing (Lampert, 2001). Third, the statement 'I feel safe to say that I am stuck in my maths lessons' was based on the awareness that learners should be encouraged to consider this stage as a valuable step for learning and to reflect on it in order "to know what to do when they don't know what to do" (Claxton, 1999, p. 70). Finally, the last two statements ('I know what a proof/conjecture is') were designed to check whether learners knew the meaning of the two terms although we were aware that they could have had different conceptions of them.

Questions 2 and 3 were designed to meet the other two desired outcomes of the questionnaire. Students had to assess the truth of two mathematical tasks, construct a proof and then evaluate their own construction stating whether they had produced a proof or not. The two mathematical tasks presented two different formulations: a general statement (e.g. 'When you add two odd numbers, the answer is always even') and a list of examples (e.g. ' $3+7=10,5+11=16,15+3$ $=18 \ldots$ What do you notice?'). The version of the questionnaire used at the end of the intervention used different (but similar) tasks for Questions 2 and 3.

Finally, Question 4 asked the students to state which of the two formulations in Questions 2 and 3 they found more helpful in order to express their mathematical ideas and to explain their thinking. This question was designed to investigate whether the way a written question is formulated could influence students' conjecturing stance and therefore play a role in developing an enquiring atmosphere in the classroom. 


\subsubsection{Prompts}

Following Shilling-Traina and Stylianides' (2013) approach, three prompts were given to the Year 9 students in order to gather information on their beliefs about some aspects of the classroom atmosphere in their mathematics lessons. The prompts were given at the beginning and at the end of the intervention and were completed during a mathematics lesson. Table 3 presents the prompts used, the time of administration, and the corresponding research questions.

\begin{tabular}{|c|c|c|}
\hline Prompts & Time of administration & Corresponding RQ \\
\hline $\begin{array}{l}\text { 1. Do you feel safe to express your } \\
\text { mathematical ideas during the lessons? } \\
\text { Why or why not? }\end{array}$ & $\begin{array}{l}\text { Beginning and end of } \\
\text { the intervention }\end{array}$ & $\begin{array}{l}\text { RQ1 } \\
\text { RQ1, RQ2 }\end{array}$ \\
\hline $\begin{array}{l}\text { 2. Do you think that it is important and } \\
\text { useful to share your mathematical ideas? } \\
\text { Why? }\end{array}$ & $\begin{array}{l}\text { Beginning and end of } \\
\text { the intervention }\end{array}$ & $\begin{array}{l}\text { RQ1 } \\
\text { RQ1, RQ2 }\end{array}$ \\
\hline $\begin{array}{l}\text { 3. Please rate how useful the following } \\
\text { activities were in order to make a } \\
\text { conjecture and write a proof by } \\
\text { placing a check mark in the } \\
\text { appropriate box ( } 1=\text { not useful at all, } \\
5=\text { very useful). } \\
\text { Note: See Appendix B for the activities. }\end{array}$ & $\begin{array}{l}\text { End of the intervention } \\
\text { only }\end{array}$ & RQ2, RQ3 \\
\hline
\end{tabular}

Table 3. Prompts, time of administration, and corresponding research questions

Prompts 1 and 2 were a reformulation of two statements presented in Question 1 of the questionnaire (see Appendix A) in order to gather more information on students' views. The two aspects in the statements were identified as key features in order to establish a classroom atmosphere where students would express their conjectures and mathematical ideas (Lampert, 2001). A comparison of the responses at the beginning and at the end of the intervention provided an insight into students' beliefs about some aspects of the classroom atmosphere and helped to analyse a possible impact of the intervention. Finally, Prompt 3 was submitted only at the end of the intervention and it helped to explore RQ2 and RQ3 by analysing the activities, strategies, and oral questions that received the highest scores in supporting learners in formulating conjectures and proofs. The effect of the written questions was evaluated through the analysis of students' responses to Question 4 of the questionnaire, as explained in Section 3.3.1.

Regarding the analysis of the prompts, the learners' responses to Prompts 1 and 2 often presented common beliefs about sharing mathematical ideas. Therefore, multiple codes were created in order to collect participants' responses (Table 4 and Table 5) and the frequencies were recorded in order to compare the students' responses at the beginning and at the end of the intervention. 


\begin{tabular}{|l|}
\hline $\begin{array}{c}\text { Do you feel safe to express your mathematical ideas during } \\
\text { the lessons? Why or why not? }\end{array}$ \\
\hline Negative 1 (NEG1): Fear of getting the answer wrong \\
\hline Negative 2 (NEG2): Fear of others' opinions \\
\hline Neutral (NEU): Express ideas only if asked \\
\hline Positive 1 (P1): Help yourself and others \\
\hline Positive 2 (P2): Not worried by others' opinions \\
\hline
\end{tabular}

Table 4. Prompt 1 codes

\begin{tabular}{|l|}
\hline $\begin{array}{c}\text { Do you think that it is important and useful to share your } \\
\text { mathematical ideas? Why? }\end{array}$ \\
\hline LM: Learn from mistakes \\
\hline LT: Learn different methods and techniques \\
\hline H: Help yourself and others to understand \\
\hline U: Let the teacher know about your understanding \\
\hline N: Not important or not useful \\
\hline
\end{tabular}

Table 5. Prompt 2 codes

In the total frequencies, a single view scored one mark while two different views in the same response scored half of a mark each in order to value every person equally. Figure 2 and Figure 3 show a sample response to Prompt 1 and Prompt 2 and the codes used to analyse it.

If I have a mathematical idea I am ok to express it (P2), because I know that if it is wrong it does not matter, I will learn (P1).

Two views: $\mathrm{P} 2, \mathrm{P} 1$

Figure 2. Sample response to Prompt 1 and coding

If someone else shares, then maybe it will help you $(\mathbf{H})$ or if they get it wrong you could explain to them how it is wrong (LM). Also if I share my idea it is the same for me.

Two views: $H, L M$

Figure 3. Sample response to Prompt 2 and coding 
Responses to Prompt 3 were recorded and the frequencies analysed in order to evaluate students' views on the impact of different activities, strategies, and oral questions in the processes of conjecturing and proving.

\subsubsection{Interviews (see Appendix C for the questions)}

Semi-structured interviews were conducted during Cycle 3 with six students (four girls and two boys) selected from the Year 9 class. Pupils were selected and paired according to their answers to Prompt 1 and to Question 2 of the questionnaire at the beginning of the intervention. The six students were divided into three groups as summarised in Table 6: group 1 was characterised by negative beliefs (NEG1) in Prompt 1 and correctly evaluated non-proof arguments as non-proofs; group 2 was characterised by positive beliefs (P1 and P2) and incorrectly considered non-proof arguments as proofs; and group 3 was characterised by positive beliefs (P2) and correctly evaluated arguments they produced as proofs. The three groups were chosen as they represented the majority of the views of the Year 9 class.

\begin{tabular}{|c|c|c|c|}
\hline & & $\begin{array}{l}\text { Responses to Prompt } 1 \\
\text { (at the beginning of the } \\
\text { project) }\end{array}$ & $\begin{array}{l}\text { Responses to Question } 2 \\
\text { (at the beginning of the project) }\end{array}$ \\
\hline \multirow[t]{2}{*}{ Group 1} & Amy & NEG1 & Non-proofs evaluated as non-proofs \\
\hline & Billie & NEG1 & Non-proofs evaluated as non-proofs \\
\hline \multirow[t]{2}{*}{ Group 2} & Carl & $\mathrm{P} 2$ & Non-proofs evaluated as proofs \\
\hline & David & $\mathrm{P} 1$ & Non-proofs evaluated as proofs \\
\hline \multirow[t]{2}{*}{ Group 3} & Eva & $\mathrm{P} 2$ & Proofs evaluated as proofs \\
\hline & Fiona & $\mathrm{P} 2$ & Proofs evaluated as proofs \\
\hline
\end{tabular}

Table 6. The three groups of students who participated in the interviews (all names are pseudonyms)

The interviews were guided by the list of questions in Appendix $\mathrm{C}$ but also explored new themes related to the research that emerged during the interviews as a result of pupils' responses. The questions were divided into two sets: enquiring atmosphere and formulating conjectures and proofs in order to better address the research questions. The questions in the first set allowed us to better understand pupils' beliefs about the classroom atmosphere and any changes from the beginning of the study. The questions in the second set allowed us to investigate to more depth students' strategies to formulate conjectures and proofs and to examine possible changes since the beginning of the intervention.

\subsubsection{Tasks (see Appendix D)}

Two task formulations were used in the research in order to investigate which one (if any) would better support learners in formulating conjectures and proofs (see Question 4 in Appendix A). In the first formulation a general statement was presented that had to be evaluated and proved (e.g. 'When you add two odd numbers, the answer is always even' - see Question 2 in Appendix A). Among the processes discussed in Section 2.1.3, we expected 'specialising and specialising back', 'conjecturing', and 'generalising' involved when proving 
a task formulated as general statement. We anticipated learners to specialise the statement in order to conjecture whether the statement was true or false. However, we were expecting that some students would have considered their examples as an acceptable proof (Coe \& Ruthven, 1994; Healy \& Hoyles, 2000; Stylianides \& Stylianides, 2009b).

In the second formulation a collection of examples was presented and learners were asked if they noticed a pattern and then to generalise it (e.g. ' $3+7=10,5+11=16,15+3=18 \ldots$ What do you notice?' - see Question 3 in Appendix A). Therefore, in contrast to the first task where the property to be proved was stated, in the second task learners had to find it and justify it. In Brown and Coles' (2000, p. 153) study, it was found that looking for "sameness led to the question 'Why?' of proof (...) and difference led to further exploration of structure”. Therefore, since the ability of finding similarities and differences seems to be at the basis of specialising and generalising (Mason \& Johnston-Wilder, 2004), we were particularly interested in seeing whether this task formulation would have encouraged learners to conjecture and generalise. We expected that the processes involved when proving a task formulated as list of examples were 'pattern observing', 'conjecturing', and 'generalising' (see Section 2.1.3 for further details about these processes).

The complete tasks are collected in Appendix D while the schedule of the lessons was already presented in Table 2. Task b in lesson 3, the 'True or False?' task in lesson 4, and task 1 in lesson 6 are examples of the general statement formulation. On the other hand, task a in lesson 3 , the 'Charlie's conjecture' task in lesson 4, the 'Think of two numbers' task in lesson 5, task 2 in lesson 6, and the task in lesson 7 are examples of the other formulation.

\subsubsection{Other}

The first author completed a journal when she reflected on relevant ideas to the research and as soon as possible after every lesson. The analysis of these journal entries was useful to inform the planning during the project and to obtain evidence of the classroom atmosphere during the evaluation of the research.

The students' written work during the lessons was also analysed in order to evaluate possible changes in conjecturing and proving during the study and the usefulness of the strategies and questions introduced. Moreover, whiteboard pictures were used as evidence of activities and strategies introduced. Finally, the transcripts from audio or video recorded lessons (lessons 5, 6 , and 7) were analysed in order to discuss possible changes in formulating conjectures and proofs by learners and the possible use of strategies and questions introduced.

\section{Results and discussion}

In this section we will present our findings. When we discuss the students' work, we will often focus on the six students we chose for the interviews. Section 4 is organised into two themes that are related to the research questions.

Firstly, Section 4.1 discusses the participants' beliefs about their mathematics classroom atmosphere, both the initial beliefs and changes that took place during the intervention. The 
discussion in Section 4.1 will help directly address RQ1 but also will partly address RQ2 by connecting the changes in the learners' beliefs with teaching practices used in the intervention.

Secondly, Section 4.2 will focus on the specific teaching practices that we introduced in the intervention to promote an enquiring classroom atmosphere. In particular we will discuss activities, strategies, and oral and written questions as summarised in Table 7. The practices will be evaluated using different research instruments, providing also a means of triangulation. This section will directly address RQ2 and RQ3.

\begin{tabular}{|c|c|}
\hline & Short description \\
\hline Activities & $\begin{array}{ll}\text { - } & \text { 3B4ME } \\
\text { - } & \text { Valuing being stuck } \\
\text { - } & \text { Think - pair - share } \\
\text { - } & \text { Think - post-it - share } \\
\text { - } & \text { Think - stand - share }\end{array}$ \\
\hline Teaching strategies & $\begin{array}{ll}\text { - } & \text { Write some examples } \\
\text { - } & \text { Write your conjecture explicitly } \\
\text { - } & \text { Use pictures to find a proof } \\
\text { - } & \text { Use words to find a proof } \\
\text { - } & \text { Use algebra to find a proof }\end{array}$ \\
\hline Oral questions & $\begin{array}{l}\text { - Can I find an example? } \\
\text { - What do I know? } \\
\text { - What do I want? } \\
\text { - Will it always work or happen? } \\
\text { - Am I convinced? }\end{array}$ \\
\hline Written questions & $\begin{array}{l}\text { - } \text { General statement } \\
\text { - } \quad \text { List of examples }\end{array}$ \\
\hline
\end{tabular}

Table 7. A summary of the practices used in the intervention

\subsection{Students' beliefs about the classroom atmosphere}

As we mentioned earlier, this discussion of the findings on the students' beliefs about their mathematics classroom atmosphere will help directly address RQ1 and indirectly RQ2. We will concentrate on changes during the intervention by evaluating responses to questionnaires, prompts, and interviews. A comparison between the Year 9 responses to Question 1 (see Questionnaire in Appendix A) at the beginning and at the end of the intervention indicates some positive percentage increases as shown in Figure 4. 


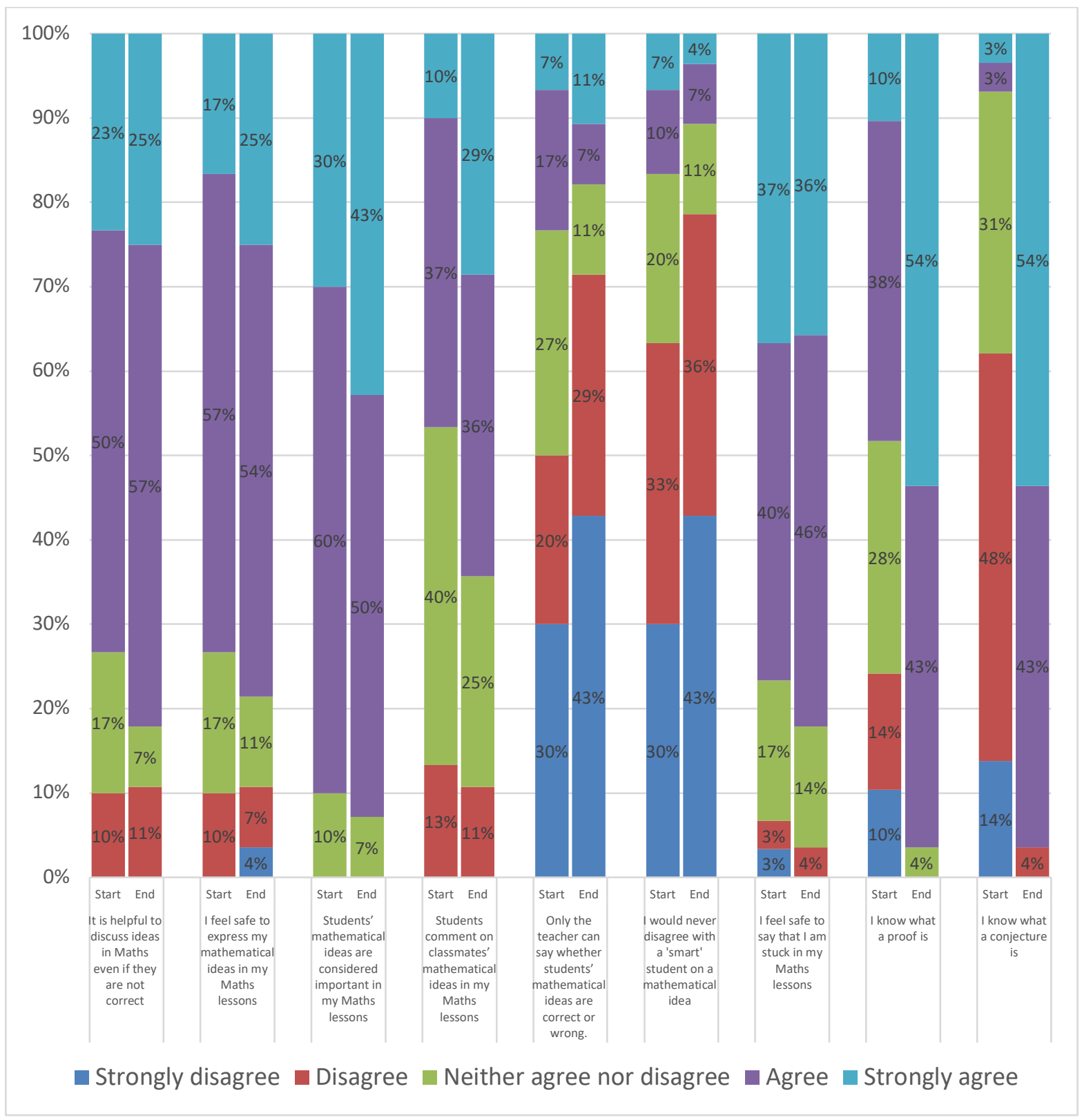

Figure 4. Year 9 students' responses to the different items of Question 1 at the beginning and at the end of the project (see Questionnaire in Appendix A)

Year 9 students' responses to Question 1 shows that the percentage of students who agreed or strongly agreed with the first three statements in Question 1 of the questionnaire increased slightly from the beginning to the end of the intervention: those who found helpful to discuss their mathematical ideas increased from $73 \%$ to $82 \%$, those who felt safe to share them increased from $74 \%$ to $79 \%$, and those who perceived their ideas valued increased from $90 \%$ to $93 \%$. Interestingly, the percentage of students who stated that classmates commented on each other's mathematical ideas considerably increased (from $47 \%$ to $65 \%$ ), as well as the percentage of those who thought that the teacher was not the only person able to judge the correctness of a mathematical statement (from 50\% to 72\%). Although Lampert (2001) states that a teacher's intervention on the interactions between students considered 'smart' and 'less smart' at mathematics by their peers is probably required in order to establish an enquiring classroom atmosphere, this did not seem necessary by the Year 9 students. Nevertheless, a 
slight increase in the percentage of students who felt confident to disagree with those considered 'smart' can be seen from the beginning to the end of the intervention $(63 \%$ versus $79 \%$, respectively) as well as of those who felt safe to say that they were stuck $(77 \%$ versus $82 \%$, respectively).

The students' responses to the prompts gave an even better insight into learners' beliefs about the classroom atmosphere. Indeed, open questions usually allow to understand pupils' ideas better than close questions (Lankshear \& Knobel, 2004).

The responses to Prompt 1 helped to highlight some beliefs that the Year 9 students had about feeling safe to share their mathematical ideas in the classroom (Figure 5). At the beginning of the intervention, $34 \%$ of the students were worried of getting the answer wrong and $15 \%$ were worried of others' opinions. Therefore, we realised that the first author had to focus on the classroom environment as Lampert (2001, p. 71) describes: she had to provide a safe environment for pupils "to reconsider their assertions, but also for them to comment on one another's assertions". The change in students' beliefs was interesting: the percentage of students who was worried about getting the answer wrong dropped from $34 \%$ to $18 \%$, and the fear of others' opinions disappeared. In contrast, the positive answers ('Not worried about others' opinions' and 'Help yourself and others') increased from $41 \%$ to $77 \%$ showing that the students felt safer to share their ideas.

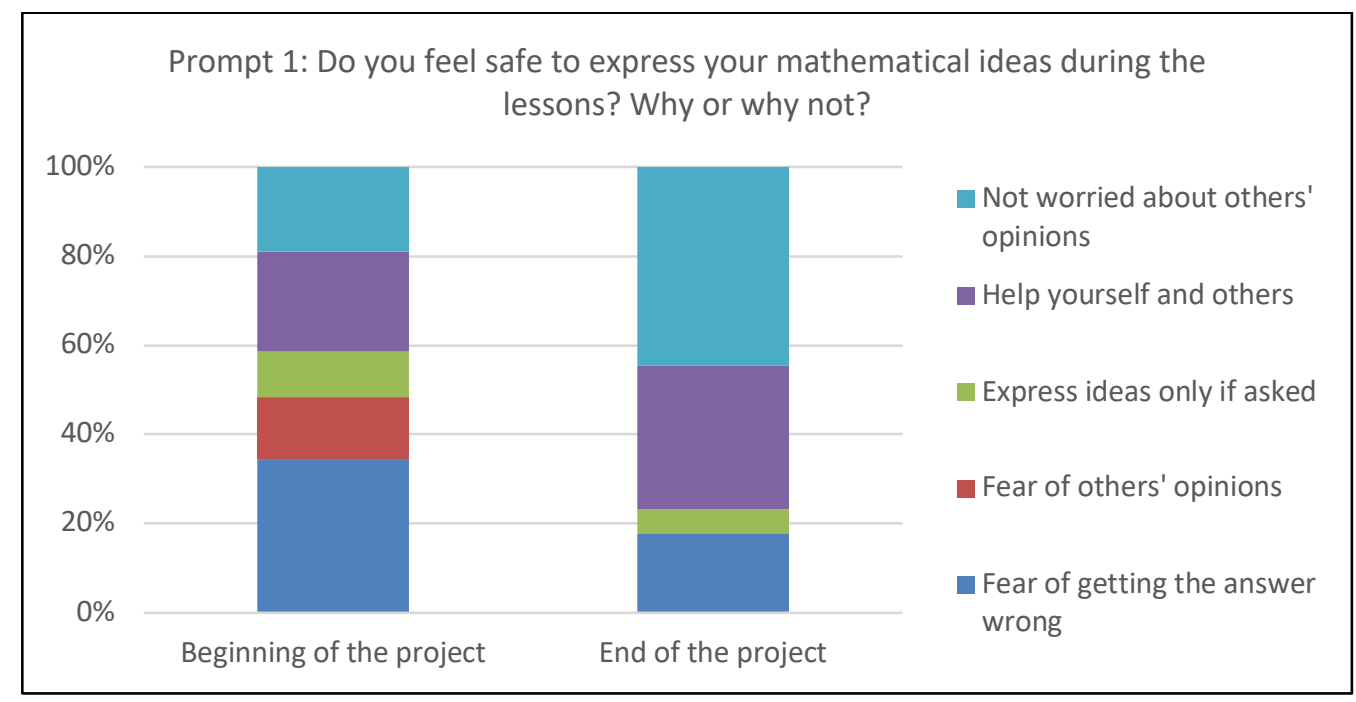

Figure 5. Students' responses to Prompt 1 at the beginning and at the end of the project

The responses to Prompt 2 helped to identify reasons for the usefulness of sharing mathematical ideas (Figure 6). While the percentage of students who thought that it was important to inform the teacher of their understanding decreased by $15 \%$, the percentage of students who recognised the importance of learning from mistakes increased by $20 \%$. At the end of the intervention $7 \%$ of the students stated that it was not important or not useful to share their ideas. 


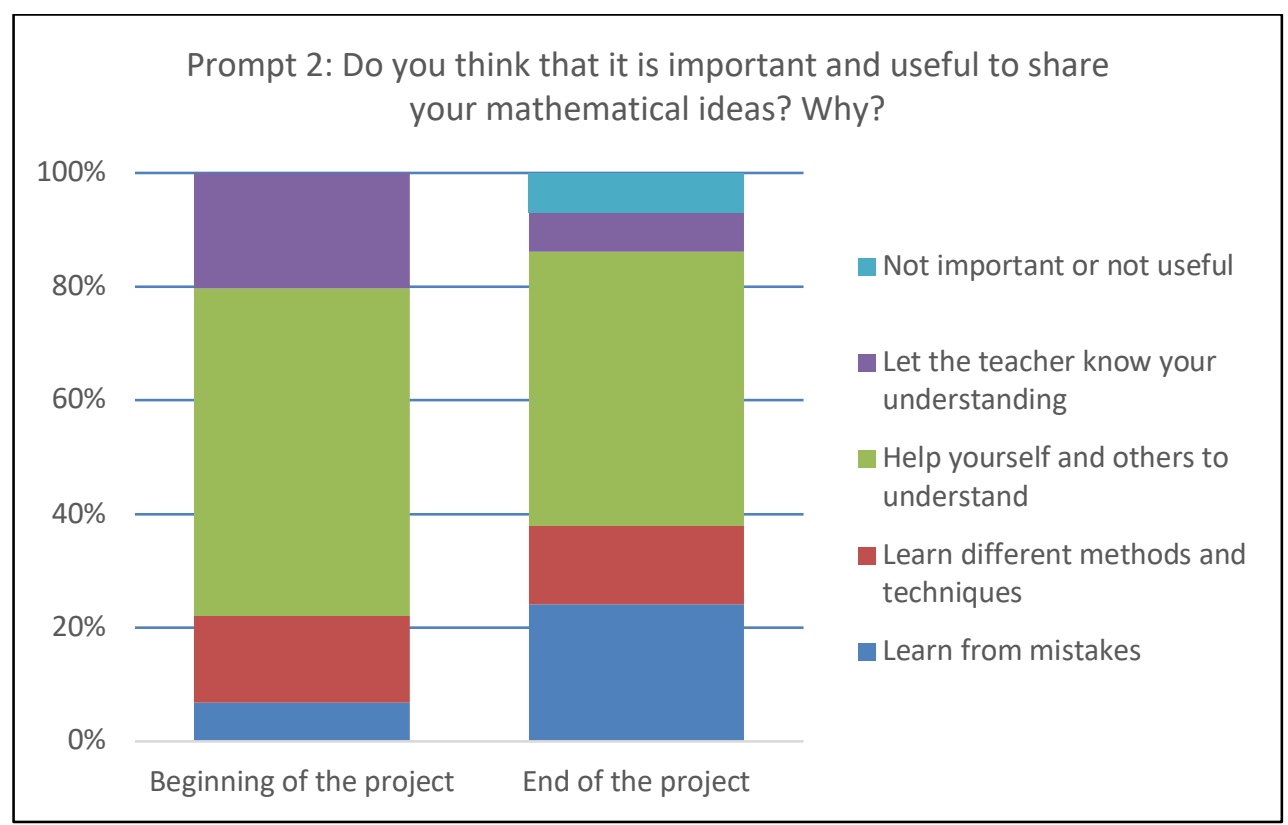

Figure 6. Students' responses to Prompt 2 at the beginning and at the end of the project

We infer that the changes in students' beliefs at the beginning and end of the intervention, as those were expressed in students' responses to Prompts 1 and 2, were influenced by the practices introduced in the research and described in detail in Section 4.2. In particular, as Yackel and Cobb (1996) mention, valuing their ideas and different conjectures encouraged them to appreciate different methods and ways of solving mathematical tasks. In the interview at the end of Cycle 3 David admitted:

David: It's nice like... tell other people how to work it out.

Related to this, Figure 5 and Figure 6 show that sharing ideas in order to help themselves and others as well as respecting others were valued by learners. Both of these behaviours had already appeared in the literature (Mason, 2002b; Lampert, 2001) as fundamental factors that promote an enquiring atmosphere. Their importance was also supported by the interview data. For example, Carl's response below illustrates students feeling safe to share their ideas (Prompt 1) and helping themselves and others by sharing their ideas (Prompt 2).

Carl: Last year people... like if you got a question wrong they could just be 'Aha, aha you got it wrong' but this year we've learnt how to not be so horrible to other people and help them instead of laughing at them.

\subsection{Teaching practices to facilitate an enquiring atmosphere}

\subsubsection{Activities}

From the analysis of the results of the questionnaire at the beginning of the intervention (Figure 4) and the first author's reflections on her teaching, we considered that the teacher needed to work with her students on the following as starting points in developing an enquiring atmosphere in her classroom: (1) the students needed to decrease their dependency on the teacher's support, (2) the students needed to value the status of being stuck, and (3) the students needed to feel comfortable to share their ideas. It seemed to us that working on these three 
points would have also encouraged students to listen to each other. This was recorded in the teacher's journal:

The atmosphere in the class is relaxed and it is a pleasure to teach this class. This is a good starting point! However, they could have a more 'mathematical involvement' in the lessons:

1. They depend on me when they are stuck.

2. They can apply their Knowledge, but they seem lost when they have to formulate new ideas.

\subsubsection{3B4ME strategy}

Regarding the first point about the need for the students to rely less on the teacher, the 3B4ME strategy (Smith, 2010) was introduced during Cycle 1 and the poster in Figure 7 was posted on the wall.

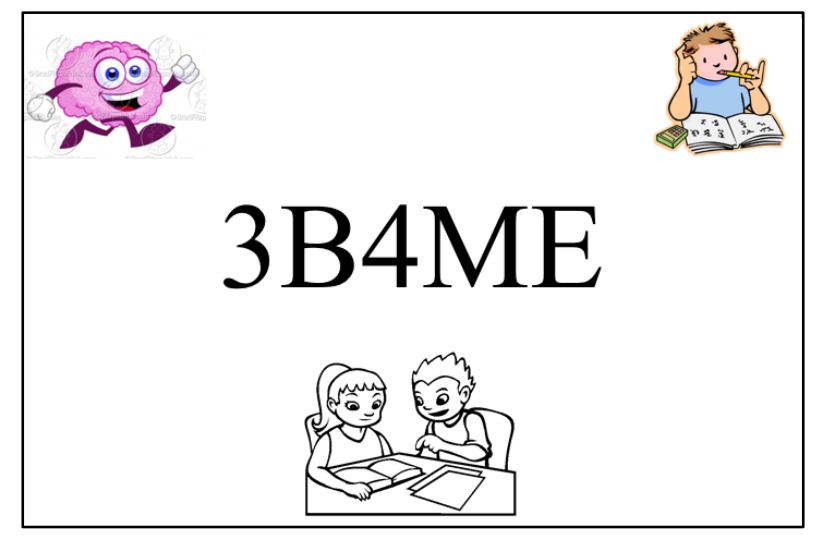

Figure 7. Poster with the 'three before me' strategy

As Lampert (2001) points out, simply stating this rule and sticking it to the wall would have not implied that this activity would have happened. During the first part of Cycle 2 the first author often had to remind learners to look in their notebooks and discuss their ideas with a friend before asking her in order to promote a classroom culture where pupils could share their ideas without expecting a teacher's comment. Bagnato and Meltzer (2010) highlight that learners' attitude to self-monitor requires time to be internalised and that their work depends on the evaluation of their progress and the consequent direction or redirection of their effort. However, reflecting on lesson 5, the first author wrote in her journal:

Now that I am thinking about it, today nobody asked me for help! They seemed to have strategies to cope with the problem (write some examples, discuss with people around them) and the pair work went really well. I even had a chance to test a new conjecture!

During the interviews in Cycle 3, pupils themselves were able to identify different stages to go through before speaking to the teacher.

Fiona: I look back in my book maybe and then I can ask someone next to me and then I would put my hand up.

Billie: I sometimes check back in my book to see if we have done anything kind of similar before and if that isn't I usually ask Lauren and then ask you. 


\subsubsection{Valuing the status of being stuck}

The second starting point in developing an enquiring atmosphere in the Year 9 classroom, which was about valuing the status of being stuck, was connected to the 3B4ME strategy. Although we wanted to provide learners with some strategies before asking for help, we felt it was also necessary to value the status of being stuck itself without the students considering it to be a failure. Two main aims were: (1) to make clear that "everyone gets stuck" and getting stuck "cannot be avoided, and it should not be hidden" (Mason et al., 1982, p. 49); and (2) to encourage students to identify key steps that could help them to become unstuck. In lesson 3 the teacher decided to explicitly talk about being stuck as a possible learning moment. The poster in Figure 8 was posted on the wall and the teacher referred back to an episode that had occurred at the beginning of the year when the teacher herself got stuck and unstuck on a problem. Indeed, as suggested by Mason (2014), seeing the teacher getting stuck and then unstuck can encourage pupils to become aware of ways to manage to get unstuck and use these by themselves.

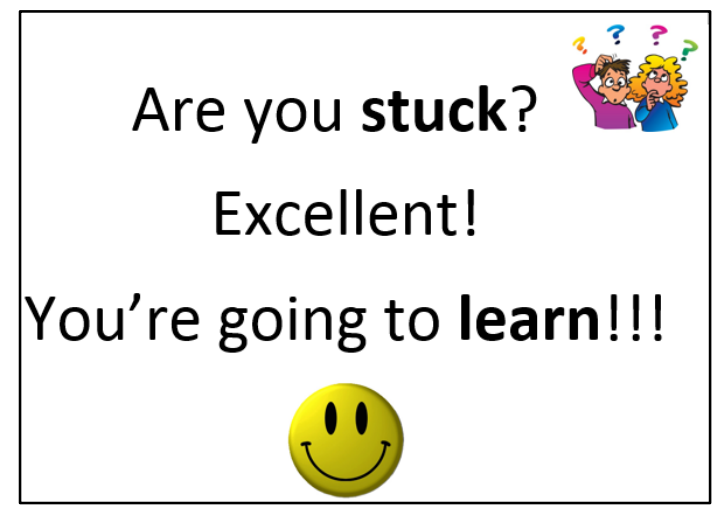

Figure 8. Poster about getting stuck

Referring back to Figure 4, we can see that, although $77 \%$ of the students already stated to feel safe in saying that they were stuck in Cycle 1, the percentage increased to $82 \%$ at the end of Cycle 3. More interestingly, the percentages of students who thought that the teacher is not the only person who can state the correctness of an answer increased from $50 \%$ to $72 \%$. This idea was also raised in the interviews with students:

Carl: When I am stuck I usually ask the people around me so... Whoever I sit next to and sometimes they will have the answer and if they don't know it then I ask the teacher but people around me mostly help me.

\subsubsection{3 'Think-...- share’ activities}

Regarding the third starting point in developing an enquiring atmosphere in the Year 9 classroom, three activities were used in the lessons in order to encourage learners to share their mathematical ideas:

1. Think - pair - share: students ponder on a task, talk with the person next to them and then share their ideas with the whole class (if necessary, the teacher will record the solutions on the whiteboard). 
2. Think - post-it - share: students ponder on a task, write their ideas/solutions on a post-it and stick it on the board to then discuss them.

3. Think - stand - share: students ponder on a task and then share their ideas/solutions with the whole class (students will record the solutions on the whiteboard).

Examples of the second and third activities are presented in Figure 9 and Figure 10.

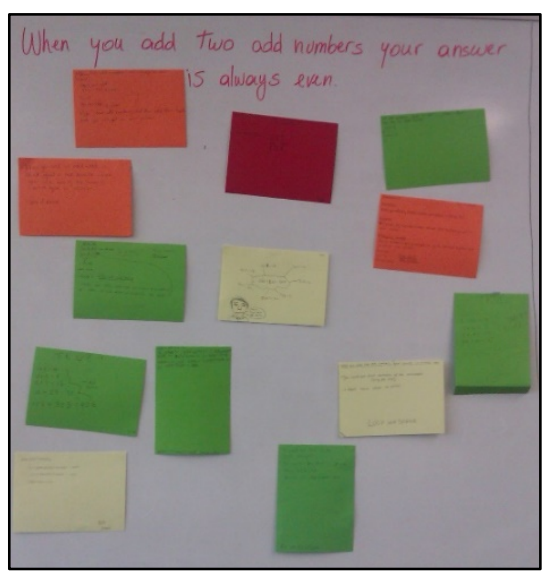

Figure 9. Think - post-it - share (lesson 2)

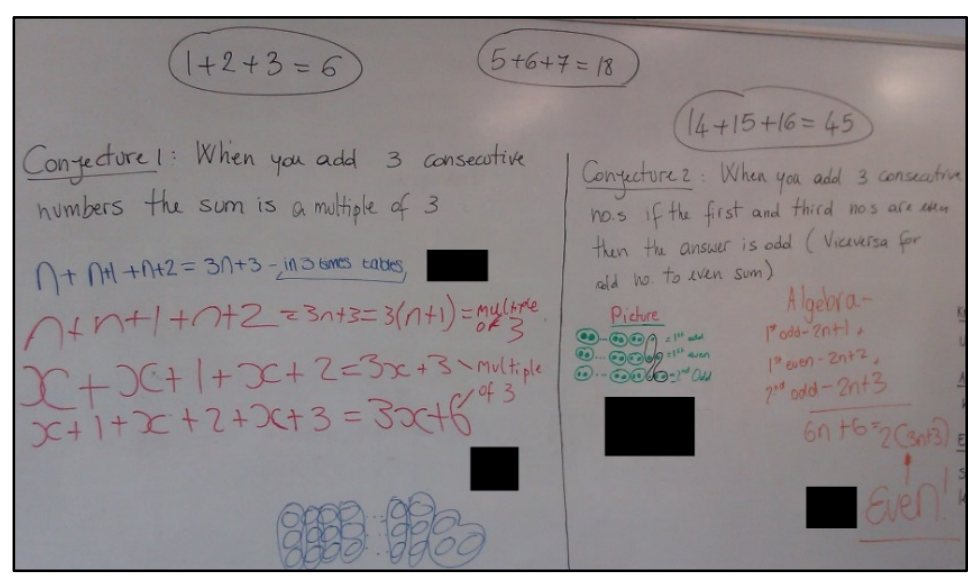

Figure 10. Think - stand - share (lesson 3)

Figure 11 presents data from students' responses to Prompt 3 (see Appendix B). The figure shows that the think-pair-share activity (without standing or using post-its) was perceived by students as the most useful from the three in terms of sharing their mathematical ideas.

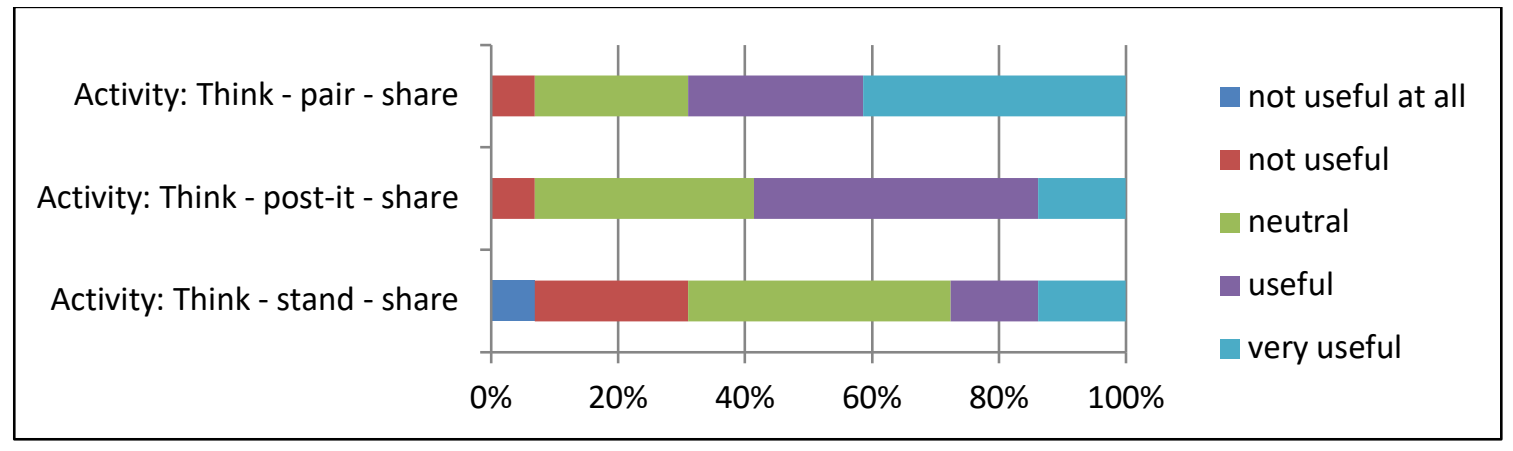

Figure 11. Students' responses to Prompt 3 at the end of the project (activities)

In the think-pair-share activity learners were given time to think through their ideas, share them with their partners, and then discuss them with the class. They appreciated when the activity involved sharing the ideas with a partner for different reasons as illustrated in the following interview excerpts.

Billie: [...] make sure more confidently that you are right if you both got the same answer and if you don't then you can work together to work out what it is.

Amy: You could work together so then if you had an idea you could develop it with each other. 
These student views reinforce the point of Sfard et al. (1998) on the importance of talking in pairs and providing reflective time in order to encourage learners to rephrase their ideas, to value them, and to contribute to create a supportive classroom environment.

Three points were always taken into consideration while the activities in Figure 11 were introduced. The first point was that, once students' conjectures or proofs had been written on the board, students were often asked to write their names next to them. As Lampert (1990) points out, writing students' names indicates that the ideas belong to the learners who formulated them and help pupils to question them rather than the teacher. However, in lesson 3 the teacher recorded the following in her journal:

Alex conjectured that the sum of three consecutive numbers is a multiple of three and he proved it using pictures. Great! But I had to ask him more than once to record his proof on the board [blue picture at the bottom of Figure 10], it seemed like he felt ashamed...

Related to this, Healy and Hoyles (2000) found out that, although students in their study preferred proofs using everyday language, they tended to produce proofs using algebra because they were more likely to receive a better grade. Being aware of this, as we will explain in the following section, we explicitly introduced the use of different representations as a helpful strategy to prove a conjecture. In this regard, it is worth noting that Alex included his pictorial proof in the final group poster on conjectures and proofs at the end of Cycle 3 (Figure 12).

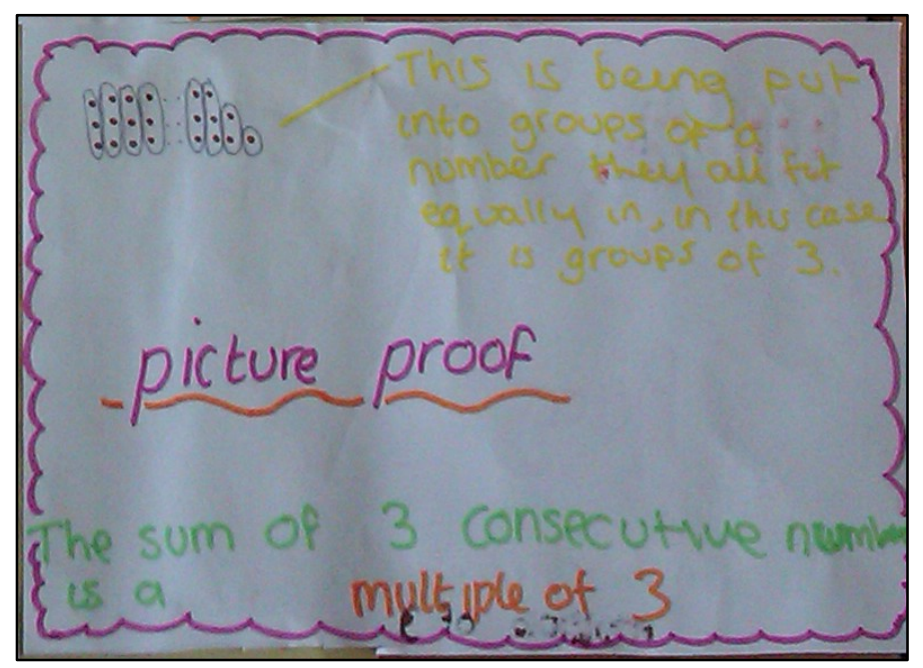

Figure 12. Alex's pictorial proof in the final poster about proofs (lesson 8)

The second point that was taken into consideration while the three activities were introduced was that, before writing students' mathematical ideas on the board, the teacher circulated in the classroom looking for ideas that would have been interesting to share and discuss according to the lesson objectives. Therefore, monitoring learners' responses allowed her to get a sense of the learning going on in the class and "to identify the mathematical learning potential of particular strategies and representations used by students" (Stein et al., 2008, p. 326). In this monitoring phase, it was invaluable the anticipating work she had done with the mathematics teachers in the department meetings in order to anticipate possible students' answers. Thus, collaborative planning should be considered as an integrated part of the 
suggestion of Stein et al. (2008) to anticipate possible learners' solutions since a richer collection of solutions can be created.

The third point that was taken into consideration while the three activities were introduced related to making purposeful choices about the order of presentation of students' conjectures and proofs in order to draw on pupils' ideas and encourage them to take part in the discussions. Indeed, according to Cobb, Wood, and Yackel (1993), it is the responsibility of the teacher to orchestrate pupils' ideas and to guide a mathematical dialogue between them. If necessary, pupils were encouraged to change their conjectures stressing the idea that changing the line of enquiry was not a failure. As an example, we present below the conversation between Max and the teacher on the effect of an enlargement for the area of the enlarged shape.

Max: If it's sf [scale factor] 2, your basic shape goes into it four times. So for every basic shape... every sf will always times two. For example sf 2 means that it goes into it four times, if it was 3 that would go into it six times.

Teacher: Ok, have you tried sf 3 and 4 ?

Max: No, I am gonna try.

Teacher: Ok!

After 9 minutes.

Max: Miss, I was incorrect. I have a second conjecture now...

Teacher: Ok good, tell me!

Max: My second conjecture is that whatever sf is, if you times it by itself and so you square it, it tells you how many shapes go into it. You don't times it by 2 but by itself.

\subsection{2 $\underline{\text { Strategies }}$}

In order to facilitate an enquiring atmosphere and support learners in conjecturing and proving, we introduced specific strategies that students could use while formulating conjectures and proofs as discussed in section 2.1.3. In brief, in this research we introduced three strategies at the beginning of Cycle 2: writing some examples, writing the conjecture explicitly, and using different ways to represent a proof (using words, algebra, or pictures).

The new strategies were well received and embedded in learners' mathematical work by the end of Cycle 3 as indicated by both looking at the work in students' notebooks and talking to them. Carl's answer to the question 'What is your approach when you attempt a proving task?' at the end of Cycle 3 was representative.

Carl: First I try to see... to find a pattern, I look at some examples and write them down, I try to find a conjecture and if I did I write it down and I try some examples with that conjecture and at the end I'll try to prove it. 
In Figure 13 we present the Year 9 students' evaluation of the strategies at the end of Cycle 3. As we can see in the figure, the students found most useful the strategies of writing some examples and using algebra to find a proof. The least useful strategy seemed to be the one about using pictures to find a proof. Next, we are going to discuss each strategy separately, explaining how each strategy was introduced and applied in the work of the class and connecting the discussion to the literature.

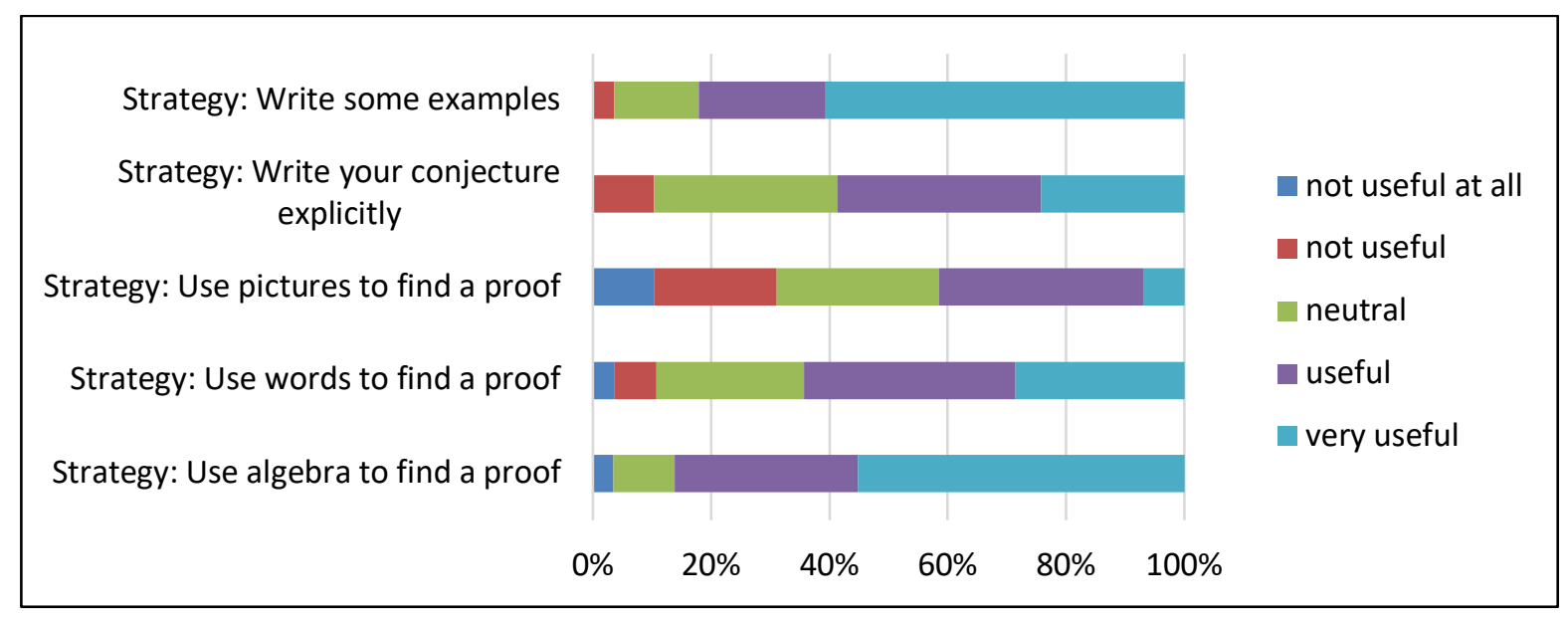

Figure 13. Students' responses to Prompt 3 at the end of the project (strategies)

\subsubsection{Write some examples}

The first strategy was suggesting learners to write some examples when they had to attempt a proof task. We introduced it for two main reasons. The first reason was that specialising should help students to get a sense of the problem and try to discover patterns. In this regard, Reid (2002) noticed that all students in his study observed patterns before attempting to conjecture and prove. Therefore, we decided to explicitly teach this strategy and the high percentage of Year 9 students who found writing examples useful to formulate conjectures and proofs $(82 \%$; see Figure 13) reinforced its usefulness. Two extracts from Amy's notebook, written in lessons 3 and 6 (Figure 14 and Figure 15, respectively), indicated that the strategy was well received and embedded in her mathematical work. 


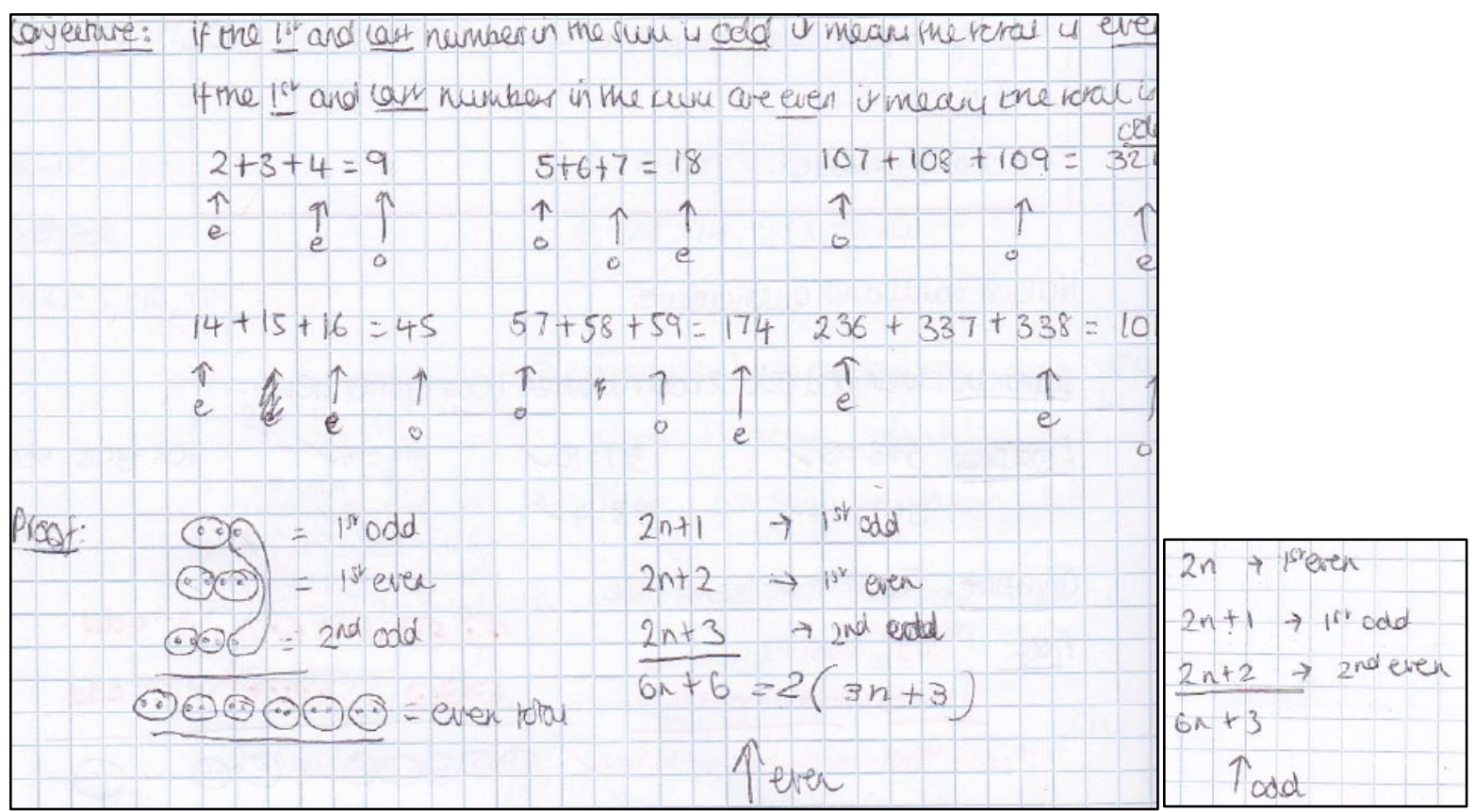

Figure 14. Amy's work on 'What do you notice when you add 3 consecutive numbers?' (lesson 3)

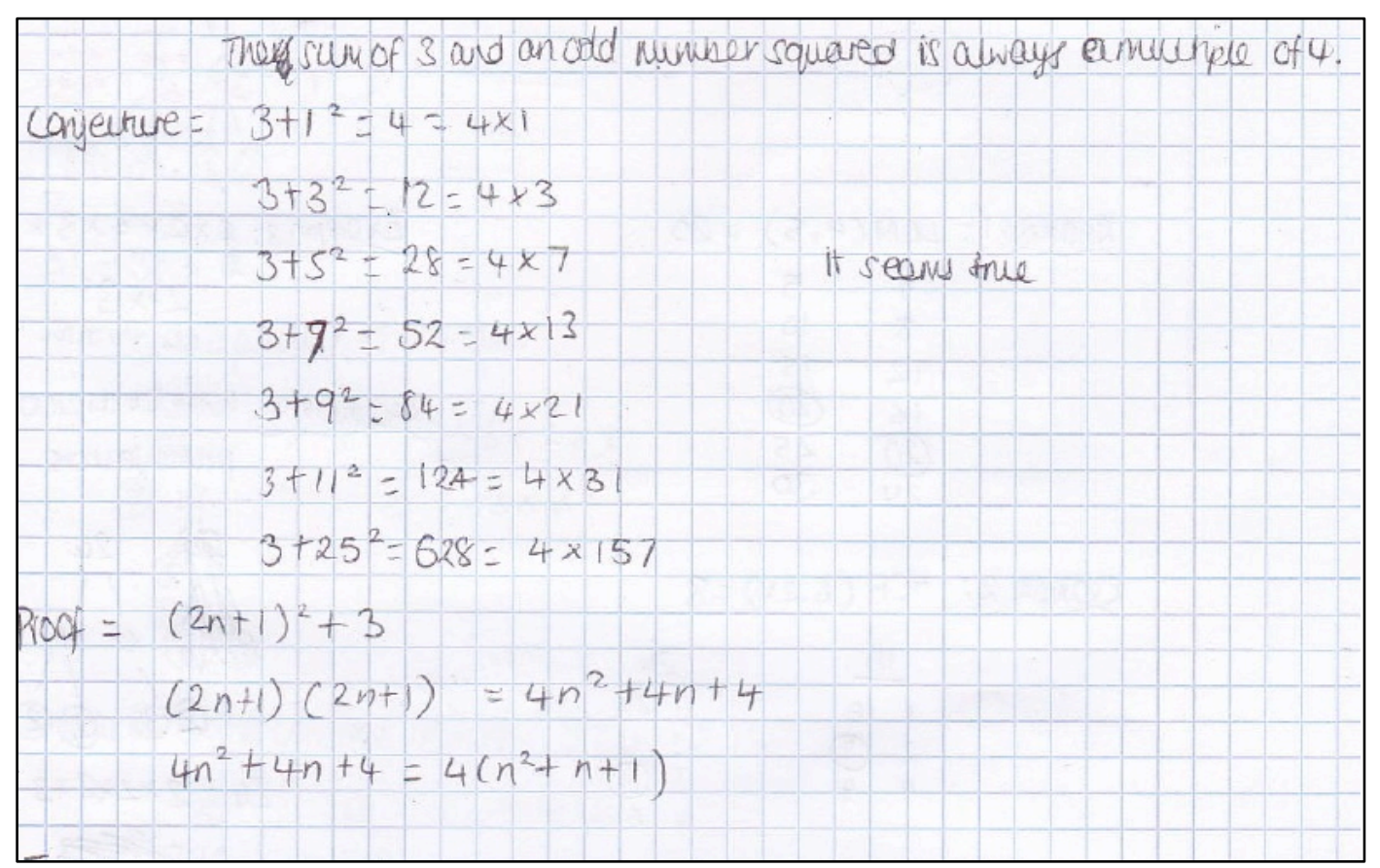

Figure 15. Amy's work on 'The sum of 3 and an odd number squared is always a multiple of 4' (lesson 6)

At the end of every lesson learners were often asked to evaluate what strategy had been helpful. Amy's comment in lesson 6 provides evidence of the importance of specialising in order to get some ideas on the task before starting to conjecture and prove.

Amy: I found examples before I thought about the conjecture and proof so I had some ideas before I started. I found this strategy very useful and easier to work with. 
In other words, this strategy helps to experience the 'getting started' and 'getting involved' states described by Mason et al. (1982). However, confirming the findings of Alcock and Inglis (2008), the students used the examples not only to get started but also to test their conjectures using crucial experiments or to produce counterexamples.

The second reason for introducing writing some examples was to emphasise that producing examples and observing patterns were strategies to support the development of arguments but did not constitute a proof. From the reviewed literature (Harel \& Sowder, 2007; Stylianides \& Stylianides 2009), we were aware that learners may think that empirical arguments are proofs. As Stylianides (2007) points out, teachers have the responsibility to help learners to realise the limitations of empirical arguments and to appreciate the role of proof to validate identified patterns. Because of this prior research, we considered that explicitly introducing the use of examples as a tool to look for conjectures and proofs can help remind learners of the limitations of empirical arguments. The interviews confirmed that the students' awareness of this strategy supported them in looking for a proof as illustrated by Fiona's interview excerpt below.

Fiona: If you use examples then you can see a pattern that take you to the proof more easily.

\subsubsection{Write the conjecture explicitly}

The second strategy was suggesting learners to write conjectures down as soon as they formulated one. As Love and Mason (1992) suggest, making note of conjectures is useful because conjectures are often transitory intuitions. Recording conjectures is worthwhile because it makes possible going back to them and it allows the students to free up their mind in order to reason them through. As shown in Figure 13, nearly $60 \%$ of Year 9 students valued this strategy in order to support them in conjecturing and proving. Billie explained why the strategy helped her in the interview at the end of Cycle 3.

Billie: I think it helps 'cause you know what direction you're trying [to go] in. So you know what you're focusing on and it makes a bit easier to work out.

Billie's assertion can be seen being put into practice in Amy's poster in lesson 8 at the end of the project (Figure 16). Amy was investigating the link between the perimeter of an enlarged shape and the original one. She clearly stated her conjecture and then wrote a proof being aware of the direction she should have taken. 


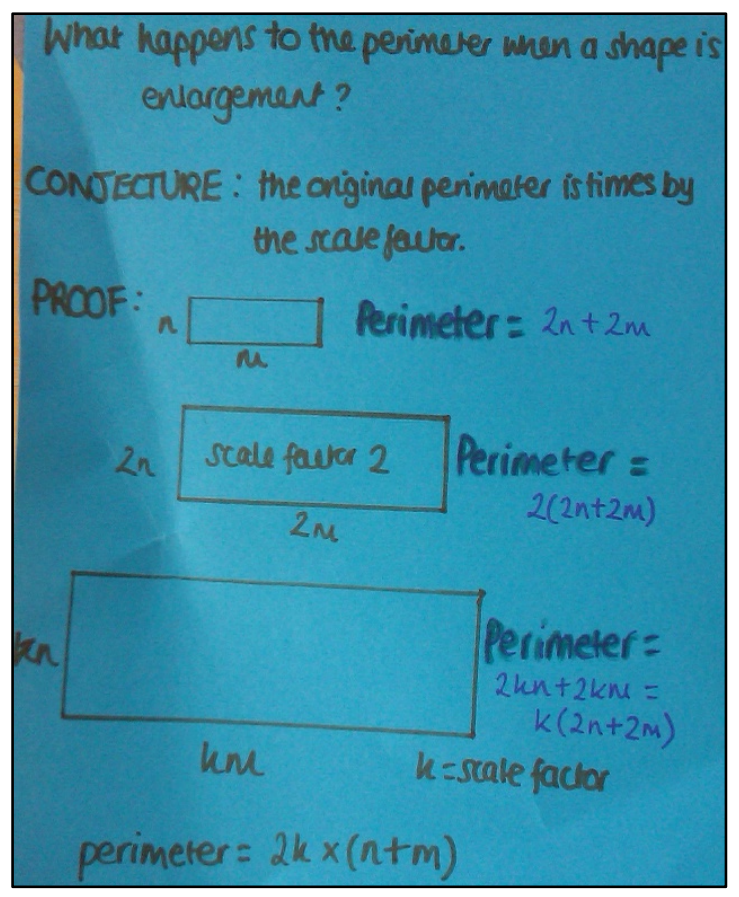

Figure 16. Amy's poster (lesson 8)

Writing conjectures down appeared to help students explicitly stating their idea when the task was investigative and a pattern had to be identified (e.g. the 'enlargement task' in Figure 16). However, when the general statement was already stated conjectures consisted in an initial evaluation of the statement correctness or a reformulation of the statement in learners' words (Figure 17).
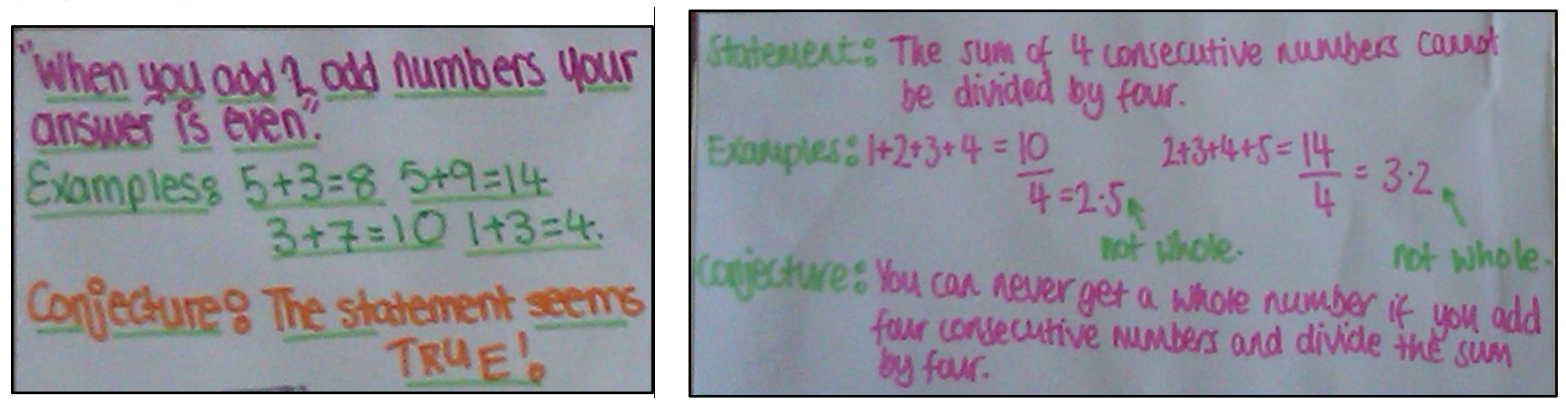

Figure 17. Posters produced by a group of students in lesson 8

Finally, writing the conjectures supported learners in revisiting their assumptions and rewriting them if necessary. David's work (Figure 18) shows that he reformulated his conjecture twice before stating the final one that led him to a proof (although his proof is not complete). As suggested by Lampert (2001), the teacher in our study deliberately taught her students to revise their conjectures when necessary, to reframe them or to modify them, emphasising to students it was perfectly acceptable for them to change their line of exploration. 


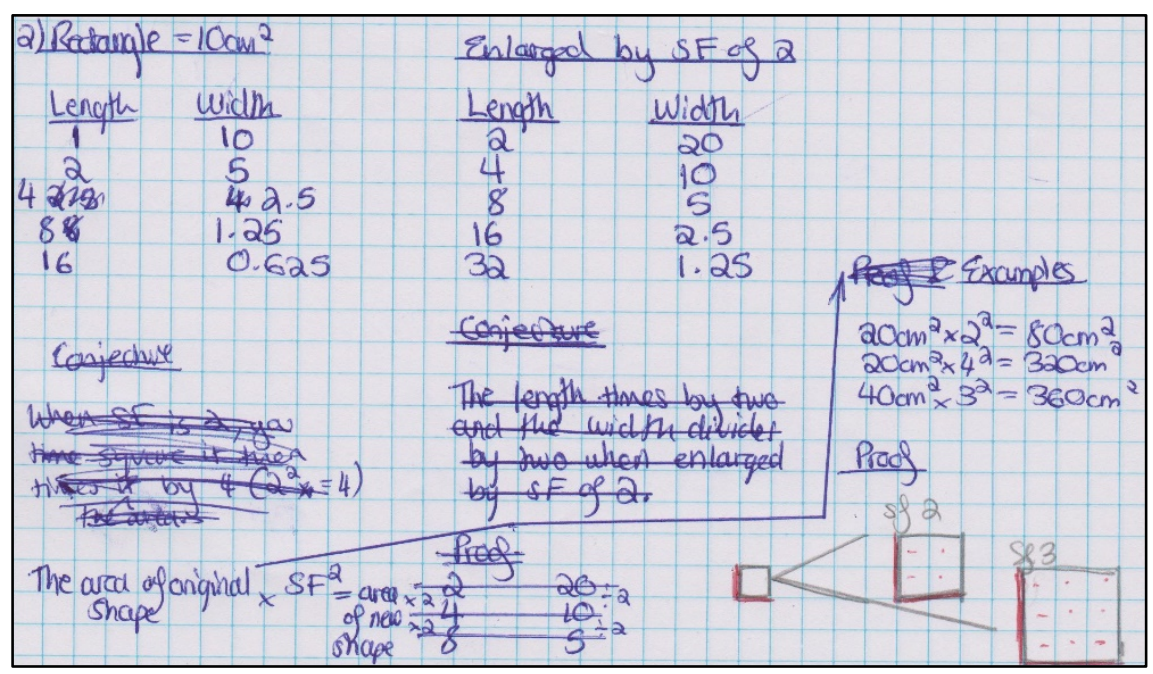

Figure 18. David's work on the effect of an enlargement on the area (lesson 7)

\subsubsection{Different proof representations}

The third strategy consisted of using three different representations to write proofs: using words, pictures, or algebra. Stylianides' (2007) definition of proof takes into consideration the importance of different representations that should be accessible or in the range of accessibility of the classroom community. The teacher recorded in her research journal the proofs that she shared with the students in lesson 3 using different representations:

Statement: The sum of two odd numbers is an even number.

\section{$\underline{\text { Words }}$}

1 st odd number $=$ even +1

2 nd odd number $=$ another even +1

1 st odd +2 nd odd $=$ even $+2=\mathcal{E} \mathcal{T E} \mathcal{N}$

(assuming that we know that even + even $=$ even)

Pictures
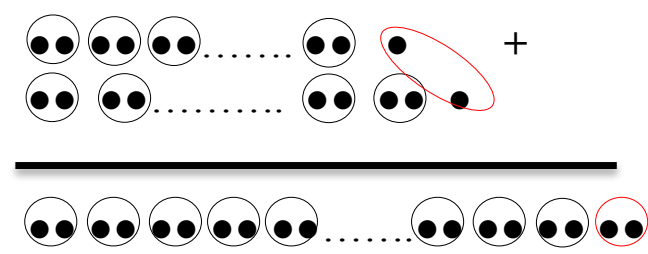

$$
\begin{aligned}
& \frac{\text { Alge6ra }}{2 n+1} \\
& 2 k \quad+1 \\
& 2 n+2 k+2=2(n+k+1)
\end{aligned}
$$


Students were then encouraged to use the representation they preferred in order to formulate a proof for particular conjectures, such as 'When you add 3 consecutive numbers, if the first and third numbers are even, then the answer is odd'. Students produced proofs using different representations, which were collected on the board at the end of lesson 3 (Figure 19).

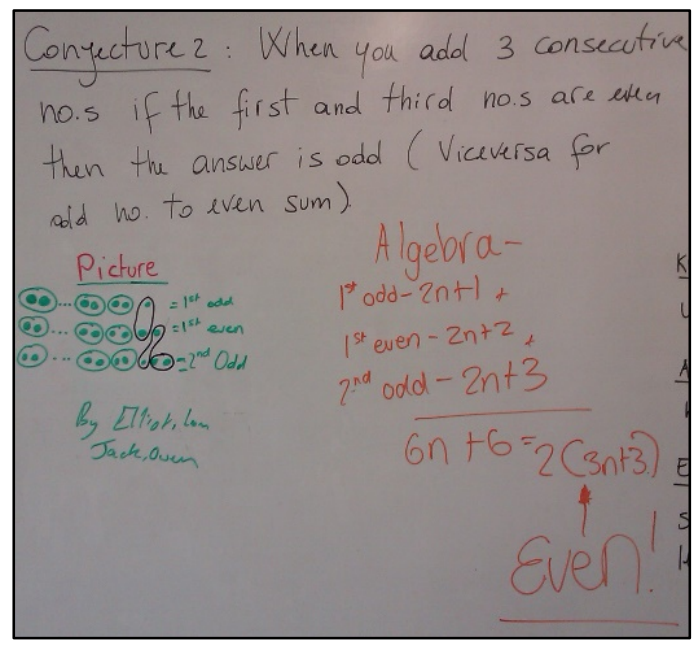

Figure 19. Students' proofs showing different representations (lesson 3)

The students' answers to Prompt 3 (Figure 13) show that almost $90 \%$ of the students in the class preferred algebraic proofs, $65 \%$ found proofs with words useful, and $41 \%$ stated that pictures were helpful to produce proofs. We would have expected a higher percentage of preferences for the pictorial proof and a lower percentage for the algebraic one. However, after a reflection on the results we were able to highlight two points. First, the Year 9 class was a high-attaining class and students had good algebraic skills. Therefore, it seemed that, as soon as students grasped how to use algebra to express generality during Cycle 2, they used it as "a succinct manipulative language in which to express and reason about generality" (Mason, 2002a, p. 119). Second, although the teacher intentionally did not associate proofs with the use of algebra, it seemed like learners valued more an algebraic proof than the others as shown by the following interview excerpts.

Carl: I prefer doing pictures first and then trying, working out with algebra.

Amy: I couldn't really work out the algebra, like I knew what it was but trying to put into algebra was really confusing so words helped a little bit in my head and then trying to translate it was hard.

Similar tendencies in the use of multiple representations have been previously identified by Amit and Fried (2005). Learners tend to start their work on a proving task by creating their own representations to support them to understand and attempt the task. Once they do that, their effort is to use more standard representations (such as algebraic representations) that may receive a higher grade or may be more appreciated by their teacher.

\subsubsection{Questions}

In addition to the activities and strategies discussed above, another focus of the research consisted of introducing specific questions to support learners in formulating conjectures and 
proofs and hence to promote an enquiring atmosphere. These were both oral questions, asked by the teacher and the students, and written questions, presented in the tasks. The selection of questions was introduced in Cycle 2 keeping in mind that, if different types of questions are used, students "are likely to pick up a sense of the subject as a richly embroidered fabric" (Watson \& Mason, 1998, p. 34).

\subsubsection{Oral questions}

We identified eight questions and divided them into those to be asked before conjecturing and those to be asked after conjecturing or proving (Table 8). As suggested by Mason (2002b), we selected a few questions as a focus for particular lessons before introducing new ones.

\begin{tabular}{|l|l|}
\hline \multicolumn{1}{|c|}{ Before conjecturing } & \multicolumn{1}{c|}{ After conjecturing/proving } \\
\hline Lesson 3 - Can I find an example? & Lesson 3 - Will it always work or happen? \\
Lesson 3 - Can I simplify the problem first? & Lesson 4 - Is it a conjecture, a fact or what? \\
Lesson 4 - What do I know? & Lesson 4 - Am I convinced? \\
Lesson 4 - What do I want? & Lesson 5 - What helped me get unstuck? \\
\hline
\end{tabular}

Table 8. Oral questions

When the questions were introduced, some posters were posted on the wall in order to make the students more familiar with them. However, in Cycle 3 the posters were removed in order not to make pupils dependent on them (Mason, 2002b). The teacher repeatedly used these questions in Cycle 2 and she referred to them indirectly in Cycle 3 by asking 'What questions do you think could help you?' or 'What could you think about?'. At the end of the lessons pupils were often asked to evaluate the questions they had used. The students were also asked to express their views about the usefulness of each of the eight questions in Prompt 3 at the end of the project. Their responses are summarised in Figure 20.

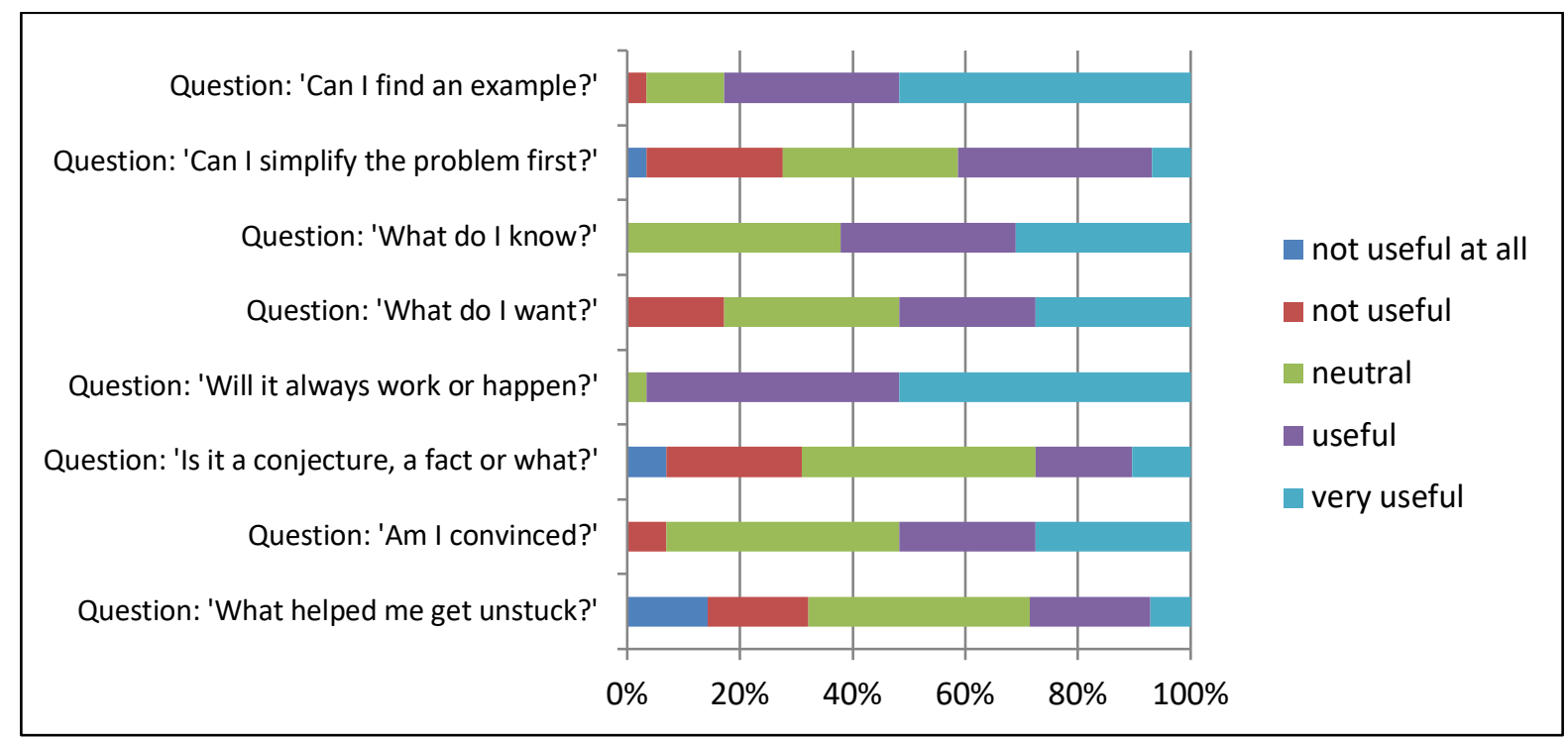

Figure 20. Students' responses to Prompt 3 at the end of the project (questions) 
Regarding the questions to be asked before conjecturing, $82 \%$ of the students found 'Can I find an example?' useful to conjecture. This is consistent with the high percentage of students who found useful the 'Writing some examples' strategy (see Figure 13). On the other hand, 'Can I simplify the problem first?' was considered not useful by $27 \%$ of the students possibly because the tasks were often subdivided in smaller tasks (Appendix D). Finally, the other two questions, 'What do I know?' and 'What do I want?' were well received by learners (only 18\% did not find the second one useful). The following excerpt from an interview at the end of the intervention offers one reason for why learners found the 'What do I want?' question useful.

Amy: 'What do you want to find out? What are you trying prove?' helps because sometimes you can go off and think... actually this is not what I am doing so thinking of that helps a lot.

Regarding the questions to be asked after conjecturing or proving, 'Will it always work or happen?' was considered useful or very useful by $97 \%$ of the students, whereas 'Is it a conjecture, a fact or what?' received less support ( $28 \%$ of the students considered it 'useful' or 'very useful'). The rationale for these two questions was to support learners in distinguishing between conjectures and proofs and, therefore, between something that seemed true and something that had been proven to be always true. In the interview Billie explained that the first question was helpful because, if she was unsure of something, it reminded her to try differently. The first question supported pupils in reminding them that a proof has to "always, always be true, without having to try every single number" (Stylianides \& Ball, 2008, p. 325) or example.

Another notable finding from Figure 20 is that the question 'Am I convinced?' was negatively rated only by $6 \%$ of the students. According to Mason et al. (1982) a proof should convince not only oneself, but also a friend and a sceptic. When in lesson 2 most of the Year 9 students were convinced that the sum of two odd numbers was an even number because it worked with some examples, the teacher had to play the role of the sceptic. Challenging their assertion by asking 'Why must the answer be even?' emphasised that "there are reasons not just facts, that statements can be justified, not just asserted" (Mason, 2001, p. 36).

In conclusion, the oral questions that were perceived more useful by learners in order to support them in conjecturing and proving were 'Can I find an example?' and 'Will it always work or happen?'. These questions were asked both by the teacher and the students to themselves and to others and contributed to promote an enquiring atmosphere in the Year 9 class. Martino and Maher (1999) emphasise the importance of teacher questioning to encourage learners to justify and generalise. On the other hand, it is also fundamental that learners use the questions themselves in order to support an enquiring atmosphere. 


\subsubsection{Written questions}

As we explained in Section 3.3.4, the tasks used in this research (see Appendix D) presented two different formulations: a general statement to be evaluated or a list of examples to be generalised. In Cycle 2, in a meeting of the mathematics teachers in the school where the intervention took place, five mathematics teachers were asked to solve the two tasks in Figure 21.

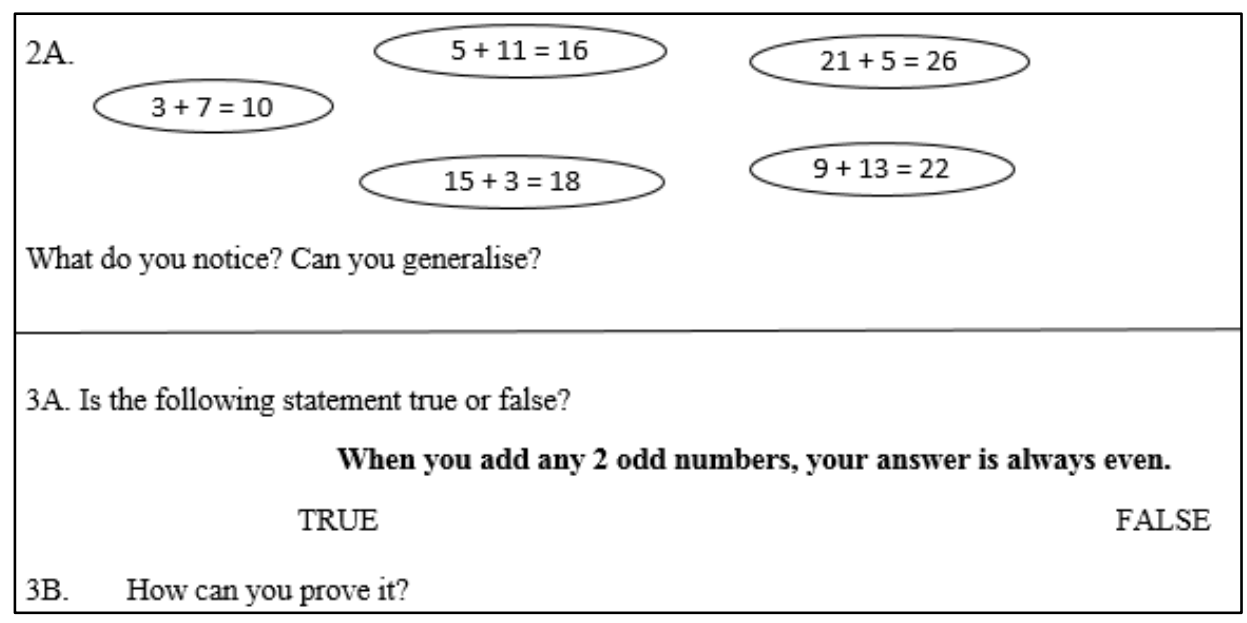

Figure 21. Tasks for teachers

The teachers were asked which task was more helpful to express their mathematical ideas and which one they thought would have been more helpful for their students. Their answers are reported in Table 9.

\begin{tabular}{|l|l|l|}
\hline & Helpful for teachers & Helpful for students \\
\hline General statement & 3 & 1 \\
\hline List of examples & 2 & 4 \\
\hline
\end{tabular}

Table 9. Teachers' answers on the tasks in Figure 21

Interestingly, most teachers thought that a list of examples would help learners to conjecture and prove more than a general statement. They explained their thinking in the following ways:

Teacher 1: It will get them trying out numbers first, then generalising before embarking on proof.

Teacher 2: They won't be so tied to proving what the teacher wants.

Similarly, Morselli (2006) highlighted the crucial role that examples play in conjecturing and proving especially in order to find out a pattern to be generalised. Therefore, we were initially struck by the answers that the Year 9 students gave to Question 4 in the questionnaire at the beginning of the project about which task was more helpful to express their mathematical ideas (Figure 22). As we can see in the figure, nearly $60 \%$ of the students preferred the general statement to the list of examples. 


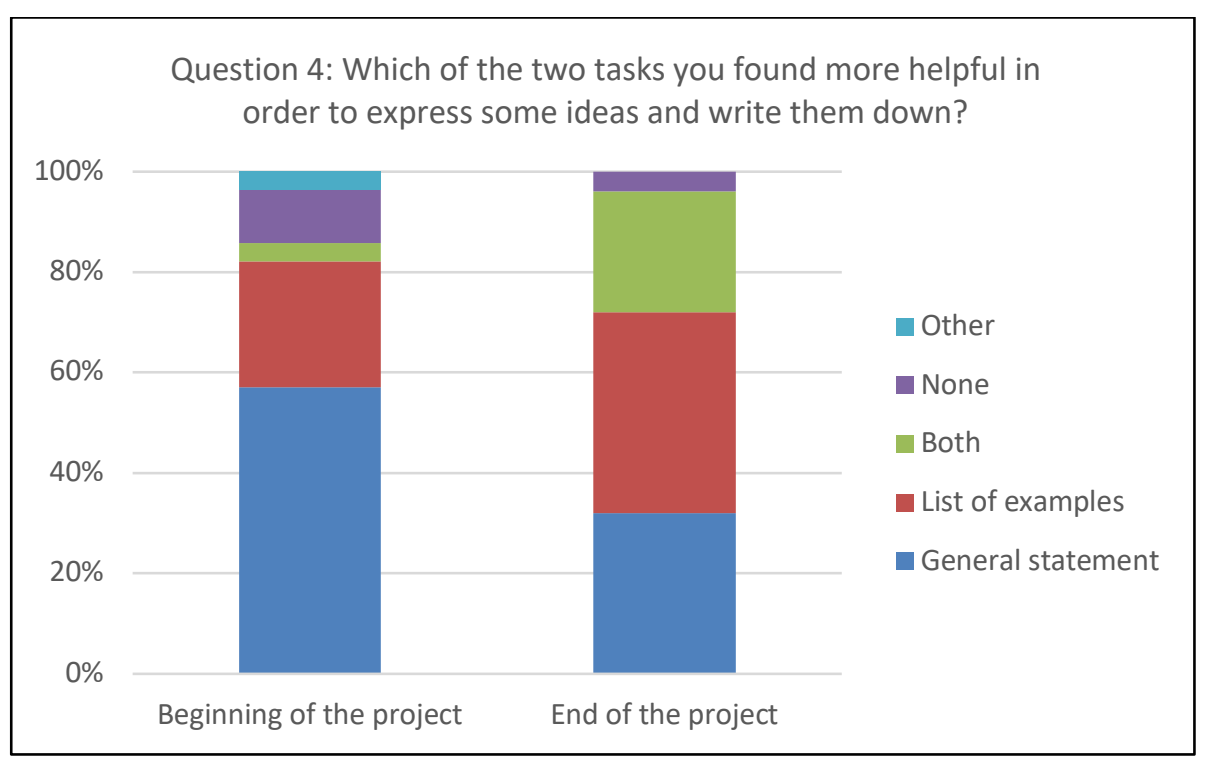

Figure 22. Students' responses to Question 4 at the beginning and at the end of the project (Questionnaire in Appendix A)

However, after the intervention the two formulations were rated almost equally by students, which might reflect the fact that the intervention included both kinds of tasks as can be seen in Appendix D. More precisely, although a third of the class still found the general statement more helpful to express their ideas, $40 \%$ of the students preferred the list of examples (as opposed to $25 \%$ at the beginning of the intervention). Some students' opinions about the two formulations can be found in the extracts from the interviews at the end of Cycle 3.

Billie: I think the general statement is easier because it is a bit already there for you.

Carl: The general statement is easier but I now prefer the example one because it is a bit more difficult... like you have to think about it first and not just straight away go ahead.

David: [referring to the list of examples] you get to know more about it and you can do harder questions with it.

At the beginning of the intervention, the general statement was often considered by students easier than the list of examples because it clearly stated what they had to prove. On the other hand, as the students above explained at the end of the intervention, the list of examples was more challenging and they were able to create their own questions. In other words, it gave them a better chance of feeling the "sense of pleasure and satisfaction of having had an idea" (Mason et al, 1982, p. 51). Furthermore, the fact that the list of examples allowed learners to formulate their own conjectures helped to promote an enquiring atmosphere in the classroom.

Figure 22 shows that, at the end of the intervention, 96\% of students found at least one of the two tasks helpful to express their ideas. This was an improvement from the beginning of the project when the corresponding percentage was $86 \%$.

In conclusion, both types of tasks seemed useful to promote an enquiring atmosphere. The general statement supported leaners in expressing what they were trying to discover and was 
a helpful reference to formulate a proof. On the other hand, the list of examples stimulated learners to pose their mathematical questions, to formulate their conjectures and investigate them. Therefore, it would be worthwhile to engage leaners in investigating tasks formulated in both ways in order to cultivate a conjecturing and enquiring atmosphere that supports pupils in "seeing connections and modifying intuitions as a result of specialising, generalizing and convincing" (Mason, 1999, p. 58).

\section{Concluding remarks}

In this paper we reported on a classroom-based intervention that lasted eight lessons with the particular focus of exploring whether and how specific activities, strategies, and questions may promote an enquiring atmosphere in a mathematics classroom, i.e., a classroom environment in which students feel safe to investigate new mathematical ideas in order to produce, share, and test their conjectures in search for a proof. Although many researchers and curriculum frameworks in different countries agree on the central role that conjectures and proofs should play in all students' mathematical experiences (e.g., Department for Education, 2013; NGA \& CCSSO, 2010), many students find it difficult to engage with conjecturing and proving. In this paper we argued that the classroom atmosphere has a crucial influence in helping students to overcome these difficulties and we focused our investigation on an English secondary mathematics classroom taught by the first author. Students' responses to questionnaires, prompts, tasks, and interview questions were analysed in order to evaluate the impact of the intervention. Although we have used a wide range of data sources to triangulate our claims in the paper, we acknowledge that students' self-reports have certain limitations in helping us understand the impact of the intervention.

Next, we will revisit the three research questions we investigated in this study (see section 3). In doing so, we will also consider implications of the study for teaching and possible directions for future research.

The first research question helped us to identify students' beliefs about their mathematics classroom atmosphere, which can influence learners' conjecturing and proving activities. Although students' answers to the closed questions in the initial questionnaire seemed mostly positive, their replies to the open questions revealed that half of the students in our study were worried to share their mathematical ideas due to a fear of making mistakes or of others' opinions. Therefore, the status of being stuck was explicitly emphasised in the intervention as a positive status to learn from and to change direction if necessary (Mason et al., 1982); moreover, following Sfard et al. (1998), apposite time was set for learners to discuss their ideas in pairs before sharing with the whole class. These strategies contributed to creating a safe classroom atmosphere in which students felt safe to offer their conjectures, discuss, and modify them. It has to be acknowledged, though, that the rather positive views of the students at the start of the intervention might be explained by the fact that the first author had already worked with the Year 9 class for a few months before the start of the intervention and, thus, even unconsciously, some ideas of this study might had already been promoted in the class's earlier work. 
The second and third research questions allowed us to investigate teaching practices and questions that may promote an enquiring atmosphere. The 'three before me' (3B4ME) strategy was used in order to promote independence. This strategy, together with the think-pair-share activity, appeared to contribute significantly to the development of a fundamental aspect of an enquiring atmosphere: everybody in the classroom became responsible to listen to others' ideas, question, and ponder on them. Moreover, three other strategies were introduced. First, learners were encouraged to write some examples in order to attack a proving task. This strategy was perceived as the most useful by learners in order to express their mathematical ideas because it stimulated them to formulate conjectures and it supported them in producing proofs. Second, pupils were invited to write their conjectures explicitly in order to learn to better express their ideas mathematically. Third, the use of different proof representations was an important factor to facilitate a classroom environment where learners were encouraged to express their conjectures and prove them using their preferred representations. These strategies contributed to promoting an enquiring atmosphere in the particular classroom where the intervention took place. An important question for future research to consider is whether the same strategies could turn out to be equally useful for other teachers in promoting an enquiring atmosphere in their own classrooms. Might it be that other features of the first author's classroom practice supported those strategies in her Year 9 classroom that could make the strategies less helpful in a classroom context where those features are absent?

Regarding the questions we used in the intervention, the oral questions 'Can I find an example?' and 'Will it always work or happen?' were perceived by students to be the most helpful. These questions supported learners in the specialising and generalising phases of the proving activity (Reid, 2002). About the written questions, at the beginning of the intervention the majority of the students stated that a formulation with a general statement (e.g. 'When you add two odd numbers, the answer is always even') was preferable to a list of examples (e.g. ' $3+7=10$, $5+11=16,15+3=18 \ldots$ What do you notice?') because it clearly states what they had to prove. However, at the end of the study, the two formulations were equally valued by the students. The list of examples often contributed to formulating different conjectures and therefore to promoting an enquiring atmosphere. Future research can explore students' views about the two formulations in different classroom environments. It is possible that the views expressed by the Year 9 students in our study were influenced by the overall focus of the teacher on the activities of conjecturing and proving. Given that such a focus is not typical of school mathematics classroom practice (Stylianides et al., 2017), it may be that students in classrooms where conjecturing and proving receive less attention will express different preferences about the two formulations.

In conclusion, our analysis suggested that specific activities, strategies, and questions can be used by teachers in order to facilitate an enquiring classroom atmosphere. However, for these to effective, the teacher needs to explicitly teach students how to listen, question, and ponder in order to give students the tools to formulate conjectures and proofs. In an enquiring atmosphere students should be taught to listen to each other, using activities that set time for learners to discuss and listen to the peers' mathematical ideas; students should be taught to question their ideas and those of others, introducing learners to sets of questions they can use and modelling the use of those questions by the teacher; and students should be taught to 
ponder, encouraging independent work and offering strategies they can use to tackle a task. Overall, our study was successful in promoting an enquiring atmosphere, it developed from existing literature on the proving activity and classroom atmosphere, and contributed new knowledge on factors that may promote an enquiring atmosphere. Being aware of how the relationship between teachers and students can influence the classroom atmosphere, it would be valuable to implement the research with other teachers and their students, keeping in mind that creating such atmosphere "is a highly complex undertaking that requires explicit effort on the part of the teacher" (Yackel \& Hanna, 2003, p. 234). 


\section{$\underline{\text { References }}$}

Ainley, J. (1987). Telling questions. Mathematics Teaching, 118, 24-26.

Alcock, L. \& Inglis, M. (2008). Doctoral students' use of examples in evaluating and proving conjectures. Educational Studies in Mathematics, 69, 111-129.

Amit, M. \& Fried, M.N. (2005). Multiple representations in $8^{\text {th }}$ grade algebra lessons: are learners really getting it? In H.L. Chick, \& J.L. Vincent (Eds.), Proceedings of the $29^{\text {th }}$ Conference of the International Group for Psychology of Mathematics Education (vol. 2, pp. 57-64). Melbourne.

Bagnato, J.S. \& Meltzer, L. (2010). Self-monitoring and self-Checking. The cornerstones of independent learning. In L. Meltzer (Ed.), Promoting Executive Function in the Classroom (pp. 160-174). New York: The Guilford Press.

Ball, D. L. \& Bass, H. (2000). Making believe: The collective construction of public mathematical knowledge in the elementary classroom. In D. Philips (Ed.), Constructivism in education: Yearbook of the National Society for the Study of Education (pp. 193-224). Chicago, IL: University of Chicago Press.

Ball, D.L. \& Bass, H. (2003). Making mathematics reasonable in school. In J. Kilpatrick, W.G. Martin, \& D. Schifter (Eds.), A research companion to Principals and Standard for School Mathematics (pp. 27-44). Reston, VA: National Council of Teachers of Mathematics.

Bieda, K.N. (2010). Enacting Proof-Related Tasks in Middle School Mathematics: Challenges and Opportunities. Journal for Research in Mathematics Education, 41(4), 351-382.

Bills, L. \& Rowland, T. (1999). Examples, generalisation and proof. In L. Brown (Ed.), Making Meaning in Mathematics: Visions of mathematics 2 (vol. 1, pp. 103-116). Advances in Mathematics Education. York, UK: QED Press.

Black, P., Harrison, C., Lee, C., Marshall, B. \& Wiliam, D. (2003). Assessment for Learning: Putting it into practice. Maidenhead: Open University Press.

Boekaerts, M. (1997). Self-regulated learning: A new concept embraced by researchers, policy makers, educators, teachers, and students. Learning and Instruction, 7(2), 161-186.

Brown, L. \& Coles, A. (2000). Same/different: A 'natural' way of learning mathematics. In T. Nakahara \& M. Koyama (Eds.), Proceedings of the $24^{\text {th }}$ Conference of the International Group for the Psychology of Mathematics Education (vol. 2, pp. 153-160). Hiroshima, Japan.

Cañadas, M. C. \& Castro, E. (2005). A proposal of categorisation for analysing inductive reasoning. In M. Bosch (Ed.), Proceedings of the 4th Congress of the European Society for Research in Mathematics Education (pp. 401-408). Saint Feliu de Guixols, Spain.

Claxton, G. (1999). Wise up: the challenge of lifelong learning. Bloomsbury, New York. 
Cobb, P., Wood, T., \& Yackel, E. (1993). Discourse, mathematical thinking, and classroom practice. In N. Minick, E. Forman, \& A. Stone (Eds.), Education and Mind: Institutional, Social, and Developmental Processes (pp. 91-115). Oxford: Oxford University Press,.

Coe, R. \& Ruthven, K. (1994). Proof practices and constructs of advanced mathematics students. British Educational Research Journal, 20, 41-53.

Cohen, H., Manion, L., \& Morrison, K. (2011). Research methods in education. Routledge: Abingdon.

Department for Education. (2013). Mathematics: Programmes of study: Key Stages 1-2 (National Curriculum in England). Retrieved from https://www.gov.uk/government/uploads/system/uploads/attachment_data/file/239129/PRIM ARY_national_curriculum_-_Mathematics.pdf.

Denscombe, M. (2010). The good research guide for small-scale social research projects $\left(4^{\text {th }}\right.$ ed.). Maidenhead: Oxford University Press.

DfES (2004). Pedagogy and practice: Teaching and learning in the secondary school unit 7: Questioning. London: HMSO.

Elliott, J. (1978). What is action-research in schools. Journal of Curriculum Studies, 10, 355357.

Fischbein, E. (1987). Intuition in science and mathematics: An educational approach. Dordrecht, Lancaster: Reidel.

Gilderdale, C. (2007). Generating curiosity in mathematics learning. [Online]. Available from: $<$ http://nrich.maths.org/5795> [Accessed 8th March 2014].

Healy, L. \& Hoyles, C. (2000). A study of proof conceptions in algebra. Journal for Research in Mathematics Education, 31(4), 396-428.

Harel, G. \& Sowder, L. (1998). Students' proof schemes. In E. Dubinsky, A. Schoenfeld, \& J. Kaput (Eds.), Research on Collegiate Mathematics Education (vol. 3, pp. 234-283). Providence: AMS.

Harel, G. \& Sowder, L. (2007). Toward comprehensive perspectives on the learning and teaching of proof. In Lester, F.K. (Ed.), Second Handbook of Research on Mathematics Teaching and Learning (pp. 805-842). Greenwich, CT, Information Age Publishing.

Hersh, R. (1993). Proving is convincing and explaining. Educational Studies in Mathematics, 24(4), 389-399.

Hodgen, J. \& Wiliam, D. (2006). Mathematics inside the black box. London: Department of Education and Professional Studies, King's College.

Ingram, J. \& Elliott, V. (2016). A critical analysis of the role of wait time in classroom interactions and the effects on student and teacher interactional behaviours. Cambridge Journal of Education, 46(1), 37-53. 
Johnston-Wilder, S. \& Mason, J. (2005). Developing thinking in geometry. London: The Open University PCP.

Knuth, E.J. (2002a). Secondary school mathematics teachers' conceptions of proof. Journal for Research in Mathematics Education, 33(5), 379-405.

Knuth, E.J. (2002b). Teachers' conceptions of proof in the context of secondary school mathematics. Journal of Mathematics Education, 5, 61-88.

Kramarski, B. \& Revach, T. (2009). The challenge of self-regulated learning in mathematics teachers' professional training. Educational Studies in Mathematics, 72(3), 379-399.

Lakatos, I. (1976). Proofs and refutations: The logic of mathematical discovery. New York: Cambridge University Press.

Lampert, M. (1990). When the problem is not the question and the solution is not the answer: Mathematical knowing and teaching. American Educational Research Journal, 27(1), 29-63.

Lampert, M. (1992). Practices and problems in teaching authentic mathematics in school. In F. Oser, A. Dick, \& J.-L. Patry (Eds.), Effective and Responsible Teaching: The New Synthesis (pp. 295-314). NY: Jossey-Bass,.

Lampert, M. (2001). Teaching problems and the problem of teaching. London: Yale University Press.

Lankshear, C. \& Knobel, M. (2004). A handbook for teacher research: from design to implementation. Buckingham: Open University Press.

Love, E. \& Mason, J. (1992). Teaching mathematics: Action and awareness. Milton Keynes: The Open University.

Martin, W.G. \& Harel, G. (1989). Proof frames of preservice elementary teachers. Journal for Research in Mathematics Education, 20(1), 41-51.

Martino, A.M. \& Maher, C.A. (1999). Teacher questioning to promote justification and generalization in mathematics: what research practice has taught us. Journal of Mathematical behaviour, 18(1), 53-78.

Mason, J. (1999). Learning and doing mathematics (2 ${ }^{\text {nd }}$ ed.). York: QED.

Mason, J (2001). Convincing myself and others. Mathematics teaching, 177, 31-36.

Mason, J. (2002a). Generalisation and algebra. Exploiting children's powers. In L. Haggarty (Ed.). Aspects of teaching secondary mathematics (pp. 105-120). Abingdon: Routledge Falmer.

Mason, J. (2002b). Minding your Qs and Rs. Effective questioning and responding in the mathematics classroom. In L. Haggarty (Ed.), Aspects of teaching secondary mathematics (pp. 248-258). Abingdon: Routledge Falmer. 
Mason, J. (2014). Questioning in Mathematics Education. In S. Lerman (Ed.), Encyclopedia of Mathematics Education (pp. 513-519). Springer Netherlands.

Mason, J., Burton, L., \& Stacey, K. (1982). Thinking mathematically. London: Addison Wesley.

Mason, J. \& Johnston-Wilder, S. (2004). Fundamental constructs in mathematics education. London: Routledge Falmer.

Mason, J. \& Johnston-Wilder, S. (2006). Designing and using mathematical tasks. York: QED Press.

Mason, J. \& Pimm, D. (1984). Generic examples: Seeing the general in the particular. Educational Studies in Mathematics, 15(3), 277-290.

Mathematical Association (Ed.) (1992). Maths talk (2 $2^{\text {nd }}$ ed.). Cheltenham: Stanley Thornes.

Mercer, N., \& Dawes, L. (2008). The value of exploratory talk. In N. Mercer \& S. Hodgkinson (Eds), Exploring talk in School: Inspired by the work of Douglas Barnes (pp. 55-72). London: Sage.

Morselli, F. (2006). Use of examples in conjecturing and proving: an explanatory study. In J. Novotnà, H. Moraovà, M. Kràtkà, \& N. Stehlikovà (Eds), Proceedings of the 30th Conference of the International Group for the Psychology of Mathematics Education (vol. 4, pp. 185-192). Prague.

National Curriculum in England (2013). Mathematics programmes of study: key stage 3. [Online]. Department for Education. Available from:

$<$ https://www.gov.uk/government/uploads/system/uploads/attachment_data/file/239058/SEC ONDARY_national_curriculum___Mathematics.pdf $>$ [Accessed 1 September 2014].

NCTM [National Council of Teachers of Mathematics]. (2000). Principles and standards for school mathematics. Reston, VA: NCTM.

National Governors Association Center for Best Practices \& Council of Chief State School Officers (NGA \& CCSSO). (2010). Common core state standards for mathematics. Washington, DC: Author.

Ollerton, M. \& Watson, A. (2001). Inclusive Mathematics 11-18. London: Continuum.

Perks, P. \& Prestage, S. (1995). Why don't they prove? Mathematics in School, 24(3), 43-45. Polya, G. (1954). Mathematics and plausible reasoning. Princeton: Princeton University Press. Polya, G. (1965). Let us teach guessing (video). [Online] Mathematical Association of America, Washington. Available from: http://vimeo.com/48768091 [Accessed 4 September 2014].

Rav, Y. (1999). Why do we prove theorems? Philosophia Mathematica, 7(1), 5-41. 
Reid, D.A. (2002). Conjecture and refutations in grade 5 Mathematics. Journal for Research in Mathematics Education, 33(1), 5-29.

Reid, D.A. (2005). The meaning of proof in mathematics education. In M. Bosch (Ed.), Proceedings of the 4th Congress of the European Society for Research in Mathematics Education (pp. 458-468). Saint Feliu de Guixols, Spain.

Reid, D.A \& Knipping, C. (2010). Proofs in mathematics education: Research, learning and teaching. Rotterdam: Sense.

Rowe, M.B. (1974). Wait time and rewards as instructional variables, their influence on language, logic and fate control. Journal of Research in Science Teaching, 11(2), 81-94.

Schoenfeld, A.H. (1985). Mathematical problem solving. London: Academic Press.

Schoenfeld, A.H. (1994). What do we know about mathematics curricula? Journal of Mathematical Behavior, 13(1), 55-80.

Sfard, A., Nesher, P., Streefland, L., Cobb, P., \& Mason, J. (1998). Learning Mathematics through Conversation; Is it as Good as they say? For the Learning of Mathematics, 18(1), 4151.

Shilling-Traina, L.N. \& Stylianides, G.J. (2013). Impacting prospective teachers' beliefs about mathematics. ZDM Mathematics Education, 45, 393-407.

Smith, J. (2010). The lazy teacher's handbook. Bancyfelin: Crown House.

Stein, M.K., Randi A.E., Smith M.S., \& Hughes E.K. (2008). Orchestrating productive mathematical discussions: Five practices for helping teachers move beyond show and tell. Mathematical Thinking and Learning, 10(4), 313-340.

Stringer, E.T. (2008). Action research in education. Upper Saddle River, NJ: Pearson Prentice Hall.

Stylianides, A.J. (2016). Proving in the elementary mathematics classroom. Oxford, UK: Oxford University Press.

Stylianides, A.J. (2007). Proof and proving in school mathematics. Journal for Research in Mathematics Education, 38(3), 289-321.

Stylianides, A.J. \& Ball, D.L. (2008). Understanding and describing mathematical knowledge for teaching: Knowledge about proof for engaging students in the activity of proving. Journal of Mathematics Teacher Education, 11, 307-332.

Stylianides, A.J. \& Stylianides, G.J. (2009a). Proof constructions and evaluations. Educational Studies in Mathematics, 72, 237-253.

Stylianides, G.J. (2008). An analytic framework of reasoning-and-proving. For the Learning of Mathematics, 28(1), 9-16. 
Stylianides, G.J., \& Stylianides, A.J. (in press). Posing new researchable questions as a dynamic process in educational research. International Journal of Science and Mathematics Education. https://doi.org/10.1007/s10763-020-10067-9

Stylianides, G.J. \& Stylianides, A.J. (2009b). Facilitating the transition from empirical arguments to proof. Journal for Research in Mathematics Education, 40(3), 314-352.

Stylianides, G. J., Stylianides, A. J., \& Weber, K. (2017). Research on the teaching and learning of proof: Taking stock and moving forward. In J. Cai (Ed.), Compendium for research in mathematics education (pp. 237-266). Reston, VA: National Council of Teachers of Mathematics.

Watson, A. \& Mason, J. (1998). Questions and prompts for mathematical thinking. Derby: ATM.

Yackel, E. \& Cobb, P. (1996). Sociomathematical norms, argumentation, and autonomy in mathematics. Journal for Research in Mathematics Education, 27(4), 458-477.

Yackel, E. \& Hanna, G. (2003). Reasoning and proof. In J. Kilpatrick, W. G. Martin, \& D. E. Schifter (Eds.), A Research Companion to Principles and Standards for School Mathematics (pp. 227-236). Reston, VA: National Council of Teachers of Mathematics.

Zack, V. (1997). 'You have to prove us wrong': proof at elementary school level. In E. Pehkonen (Ed.), Proceedings of 21st Conference of the International Group for the Psychology of Mathematics Education (vol. 4, pp. 291-298). Lahti, University of Helsinki.

Zazkis, R. \& Liljedahl, P. (2002). Generalization of patterns: The tension between algebraic thinking and algebraic notation. Educational Studies in Mathematics, 49(3), 379-40. 


\section{Appendix A. Questionnaire}

This appendix contains the questionnaire used during the research. It was submitted at the beginning and at the end of the intervention with different (but similar) tasks for Questions 2 and 3.

\section{Questionnaire}

1. Please rate how strongly you agree or disagree with each of the following statements by placing a check mark in the appropriate box.

\begin{tabular}{|c|c|c|c|c|c|}
\hline & $\begin{array}{l}\text { strongly } \\
\text { disagree }\end{array}$ & disagree & $\begin{array}{c}\text { neither } \\
\text { agree } \\
\text { nor } \\
\text { disagree }\end{array}$ & agree & $\begin{array}{l}\text { strongly } \\
\text { agree }\end{array}$ \\
\hline $\begin{array}{l}\text { It is helpful to discuss ideas in maths } \\
\text { even if they are not correct }\end{array}$ & $\square$ & $\square$ & $\square$ & $\square$ & $\square$ \\
\hline $\begin{array}{l}\text { I feel safe to express my mathematical } \\
\text { ideas in my maths lessons }\end{array}$ & $\square$ & $\square$ & $\square$ & $\square$ & $\square$ \\
\hline $\begin{array}{l}\text { Students' mathematical ideas are } \\
\text { considered important in my maths } \\
\text { lessons }\end{array}$ & $\square$ & $\square$ & $\square$ & $\square$ & $\square$ \\
\hline $\begin{array}{l}\text { Students comment on classmates' } \\
\text { mathematical ideas in my maths lessons }\end{array}$ & $\square$ & $\square$ & $\square$ & $\square$ & $\square$ \\
\hline $\begin{array}{l}\text { Only the teacher can say whether } \\
\text { students' mathematical ideas are correct } \\
\text { or wrong }\end{array}$ & $\square$ & $\square$ & $\square$ & $\square$ & $\square$ \\
\hline $\begin{array}{l}\text { I would never disagree with a 'smart' } \\
\text { student on a mathematical idea }\end{array}$ & $\square$ & $\square$ & $\square$ & $\square$ & $\square$ \\
\hline $\begin{array}{l}\text { I feel safe to say that I am stuck in my } \\
\text { maths lessons }\end{array}$ & $\square$ & $\square$ & $\square$ & $\square$ & $\square$ \\
\hline I know what a proof is & $\square$ & $\square$ & $\square$ & $\square$ & $\square$ \\
\hline I know what a conjecture is & $\square$ & $\square$ & $\square$ & $\square$ & $\square$ \\
\hline
\end{tabular}

2A. Is the following statement true or false?

When you add any 2 odd numbers, your answer is always even. 
2B. How can you prove it?

2C. Do you think that you have produced a proof in $2 \mathrm{~B}$ ?

YES

$\mathrm{NO}$

Why?

3A.

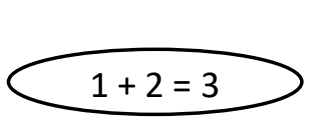

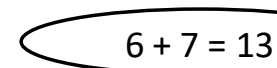

$10+11=21$
$33+34=67$

$20+21=41$

What do you notice? Can you generalise?

Hint: you are adding consecutive numbers, i.e. numbers which are one after another.

3B. If you generalised, how can you prove it?

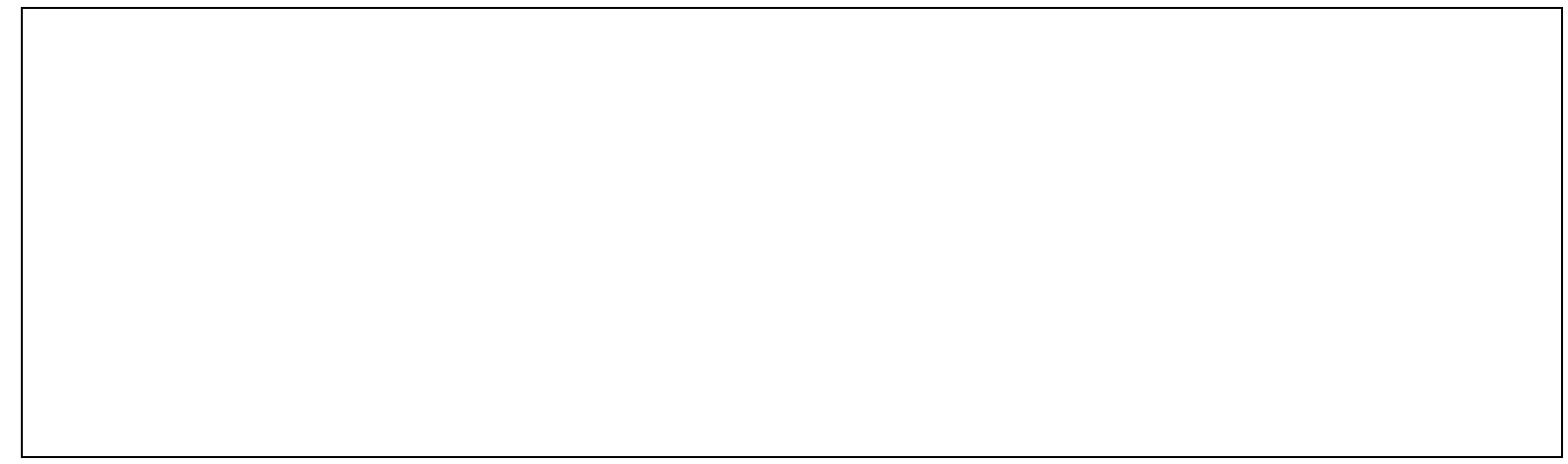


3C. Do you think that you have produced a proof in $3 \mathrm{~B}$ ?

YES

NO

Why?

4. In question 2 above, you were given a task in which you had a general statement and you had to decide if it was always true or false.

In question 3 above, you were given a task in which you had some examples, you had to identify a pattern and to decide if it was always true or false.

Which of the two tasks you found more helpful in order to express some ideas and write them down?

○ The first task

- The second task

○ Both of them

- None of them

$\circ$ Other

Explain your answer. 


\section{Appendix B. Activities in prompt 3}

This appendix contains the activities presented in Prompt 3 at the end of the research to the Year 9 class.

Please rate how useful the following activities were in order to make a conjecture and write a proof by placing a check mark in the appropriate box $(1=$ not useful at all, $5=$ very useful $)$.

\begin{tabular}{|c|c|c|c|c|c|}
\hline & 1 & 2 & 3 & 4 & 5 \\
\hline Activity: Think - pair - share & $\square$ & $\square$ & $\square$ & $\square$ & $\square$ \\
\hline Activity: Think - post-it - share & $\square$ & $\square$ & $\square$ & $\square$ & $\square$ \\
\hline Activity: Think - stand - share & $\square$ & $\square$ & $\square$ & $\square$ & $\square$ \\
\hline Strategy: Write some examples & $\square$ & $\square$ & $\square$ & $\square$ & $\square$ \\
\hline Strategy: Write your conjecture explicitly & $\square$ & $\square$ & $\square$ & $\square$ & $\square$ \\
\hline Strategy: Use pictures to find a proof & $\square$ & $\square$ & $\square$ & $\square$ & $\square$ \\
\hline Strategy: Use words to find a proof & $\square$ & $\square$ & $\square$ & $\square$ & $\square$ \\
\hline Strategy: Use algebra to find a proof & $\square$ & $\square$ & $\square$ & $\square$ & $\square$ \\
\hline Question: 'Can I find an example?' & $\square$ & $\square$ & $\square$ & $\square$ & $\square$ \\
\hline $\begin{array}{l}\text { Question: 'Can I simplify the problem } \\
\text { first?' }\end{array}$ & $\square$ & $\square$ & $\square$ & $\square$ & $\square$ \\
\hline Question: 'What do I know?' & $\square$ & $\square$ & $\square$ & $\square$ & $\square$ \\
\hline Question: 'What do I want?' & $\square$ & $\square$ & $\square$ & $\square$ & $\square$ \\
\hline $\begin{array}{l}\text { Question: 'Will it always work or } \\
\text { happen?' }\end{array}$ & $\square$ & $\square$ & $\square$ & $\square$ & $\square$ \\
\hline $\begin{array}{l}\text { Question: 'Is it a conjecture, a fact or } \\
\text { what?' }\end{array}$ & $\square$ & $\square$ & $\square$ & $\square$ & $\square$ \\
\hline Question: 'Am I convinced?' & $\square$ & $\square$ & $\square$ & $\square$ & $\square$ \\
\hline Question: 'What helped me get unstuck?' & $\square$ & $\square$ & $\square$ & $\square$ & $\square$ \\
\hline
\end{tabular}




\section{Appendix C. Interview questions}

This appendix contains a list of questions asked during the interviews in Cycle 3.

\section{Set A - Enquiring atmosphere}

- How would you describe the atmosphere in your maths classroom?

- How do you feel about sharing your ideas on a task and your conjectures on how to solve a problem?

- Do you think that there are 'smart' students at maths in your class? Would you disagree with them?

\section{$\underline{\text { Set B - Formulating conjectures and proofs }}$}

- What is your approach when you attempt a proving task?

- What do you usually do when you do not know how to solve a task or you are stuck?

- What task formulation do you prefer? Why?

- In another class, a teacher wants to present proving tasks to her/his students. Have you got any suggestions to give her/his students (useful strategies, presentation, time, resources)?

- After showing tasks presented in the questionnaires and/or other tasks solved in class:

$>$ How did you find these tasks?

$>$ How would you describe what you did? How do you know that you have/have not found a proof?

Did you use any particular strategies to attempt/solve it? 


\section{Appendix D. $\underline{\text { Tasks }}$}

This appendix contains the tasks used in Lessons 3, 4, 5, 6, and 7.

Lesson 3 (consecutive sums)

The task was inspired by the 'Summing consecutive numbers' task from the NRICH website (https://nrich.maths.org/summingconsecutive).

\section{Your task}

a) What is the same and what is different? Can you generalise?

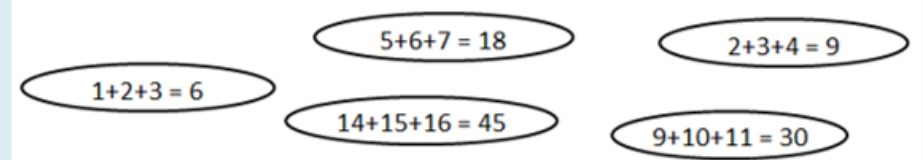

b) The sum of four consecutive numbers cannot be divided by four. Investigate!

c) Investigate the sums of five consecutive numbers and make your own conjecture.

\section{Lesson 4 (unit fractions)}

The task was adapted from the 'Keep it simple' task from the NRICH website (https://nrich.maths.org/keepitsimple).

\section{True or false?}

\section{Unit fractions can be written as the sum of two different unit fractions.}

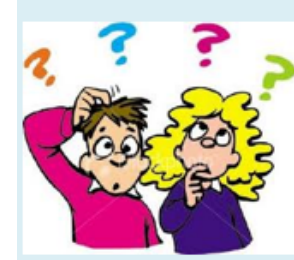

Why?

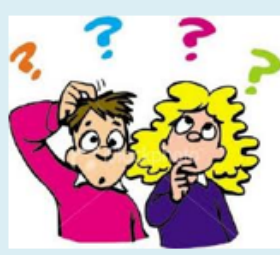




\section{Charlie's conjecture}

For example

$\frac{1}{2}=\frac{1}{3}+\frac{1}{6}$

Charlie thought he'd spotted a rule and made up some more examples.

$\frac{1}{2}=\frac{1}{10}+\frac{1}{20}$

$\frac{1}{3}=\frac{1}{4}+\frac{1}{12}$

$\frac{1}{3}=\frac{1}{7}+\frac{1}{21}$

$\frac{1}{4}=\frac{1}{5}+\frac{1}{20}$

Are all his examples correct?

What do you notice about the sums that are correct?

Find some other correct examples..

How would you explain to Charlie how to generate lots of correct examples?

\section{Lesson 5 (think of two numbers)}

The task was adapted from the 'Think of two numbers' task from the NRICH website (https://nrich.maths.org/thinkoftwonumbers).

Think of Two Numbers

Think of two whole numbers under 10

Take one of them and add 1

Multiply by 5

Add 1 again

Double your answer

Subtract 1

Add your second number Add 2

Double Again

Subtract 8

Halve this number and tell me your answer

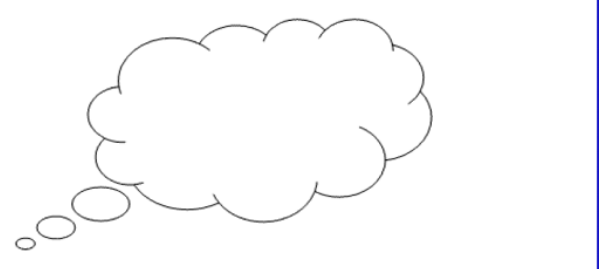

Try with different numbers until you see how it works and then you'll be ready to amaze your friends!

Thousands more problems can be found on the NRICH Maths website:

\section{Lesson 6 (number tasks)}

The tasks are grouped by difficulty: red (basic), amber (medium), green (difficult). The tasks were adapted from Mason (1999). 


\section{$\underline{\text { RED TASK } 1}$}

Write down a general description of all numbers which are seven more than the square of a number which is itself one more than a number divisible by four.

Is it always, sometimes or never true that they are all divisible by eight?

\section{RED TASK 2}

$3+1^{2}=4=4 \times 1$

$3+3^{2}=12=4 \times 3$

$3+5^{2}=28=4 \times 7$

$3+7^{2}=52=4 \times 13$

$3+9^{2}=84=4 \times 21$

What do you notice? Can you generalise?

\section{$\underline{\text { AMBER TASK } 1}$}

Write down a general description of all numbers which are eleven more than the square of a number which is itself one more than a number divisible by six.

Is it always, sometimes or never true that they are all divisible by twelve?

\section{AMBER TASK 2}

$2^{2} \times \frac{2}{3}=2+\frac{2}{3}$

$3^{2} \times \frac{3}{8}=3+\frac{3}{8}$

$4^{2} \times \frac{4}{15}=4+\frac{4}{15}$

What do you notice? Can you generalise?

\section{GREEN TASK 1}

The sum of the cubes of the first $\mathrm{N}$ integers is the square of the sum of those integers.

Is it always, sometimes or never true?

\section{GREEN TASK 2}

$4^{2}=16$

$34^{2}=1156$

$334^{2}=111556$

What do you notice? Can you generalise? 


\section{Lesson 7 (enlargements)}

The task was adapted from the 'Growing rectangles' task from the NRICH website (https://nrich.maths.org/6923).

\section{Your task}

- What happens to the area of a rectangle if you enlarge it by a scale factor of 2 ? Or 3 ? Or $4 \ldots$ ?

- What happens to the area of a rectangle if you enlarge it by a fractional scale factor?

- What happens to the area of a rectangle if you enlarge it by a scale factor of $k$ ?

- Explain and justify any conclusions you come to. Do they apply to plane shapes other than rectangles?

- Now explore what happens to the surface area and volume of different cuboids when they are enlarged by different scale factors.

Explain and justify any conclusions you come to. 